UNIVERSIDADE ESTADUAL PAULISTA

INSTITUTO DE BIOCIÊNCIAS - UNESP

PROGRAMA DE PÓS-GRADUAÇÃO EM CIÊNCIAS DA MOTRICIDADE

EFEITOS DO EXERCíCIO NOS PARÂMETROS DO ANDAR DE IDOSAS

Jozilma de Medeiros Gonzaga

Orientadora: Prof ${ }^{\mathrm{a}} \mathrm{Dr}^{\mathrm{a}}$ Lilian Teresa Bucken Gobbi

RIO CLARO - SP

2010 
JOZILMA DE MEDEIROS GONZAGA

\section{EFEITOS DO EXERCÍCIO NOS PARÂMETROS DO ANDAR DE IDOSAS}

Tese apresentada ao Programa de Pós-Graduação em Ciếncias da Motricidade, como requisito parcial para a obtenção do título de Doutora em Ciências da Motricidade, área de concentração em Biodinâmica da Motricidade Humana.

Orientadora: Prof ${ }^{\mathrm{a}}$ Dr ${ }^{\mathrm{a}}$ Lilian Teresa Bucken Gobbi

RIO CLARO - SP

2010 
796.19 Gonzaga, Jozilma de Medeiros

G642e Efeitos do exercício nos parâmetros do andar de idosas / Jozilma de Medeiros Gonzaga. - Rio Claro : [s.n.], 2010

70 f. : il., gráfs., tabs.

Tese (doutorado) - Universidade Estadual Paulista, Instituto de Biociências de Rio Claro

Orientador: Lilian Teresa Bucken Gobbi

1. Educação física adaptada. 2. Cinemática. 3.Capacidade funcional. I. Título.

Ficha Catalográfica elaborada pela STATI - Biblioteca da UNESP

Campus de Rio Claro/SP 


\section{AGRADECIMENTOS}

- A Professora Dra Lilian Teresa Bucken Gobbi, pela segura orientação e pelos exemplos de competência e simplicidade, que contribuíram não apenas para o conteúdo científico deste trabalho, mas também como crescimento pessoal;

- A Sandy Gonzaga de Melo, pelo apoio científico, companheirismo e carinho sempre constante;

- As Professoras Goretti Lisboa, Giselly Coutinho e Sandra Benício por compartilhar o desenvolvimento da pesquisa e pela amizade;

- Aos Colegas do DINTER pela agradável convivência e amizade;

- A Alisson de Almeida Melo e Fábio Augusto Barbieri, pelo apoio técnicocientífico, imprescindível para a realização deste trabalho;

- Aos Alunos do LAFIB e dos Projetos de Extensão, pela colaboração inestimável durante a pesquisa;

- Em especial aos Idosos, pela participação e colaboração para o desenvolvimento dessa pesquisa. 
Página

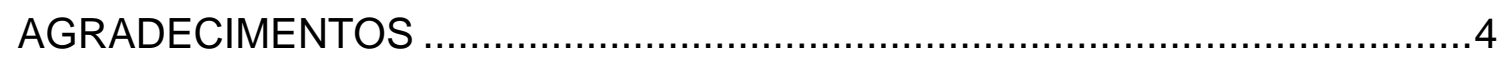

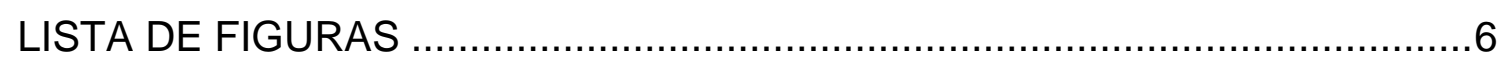

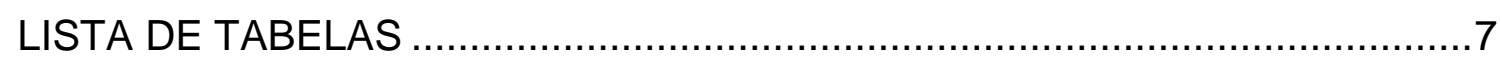

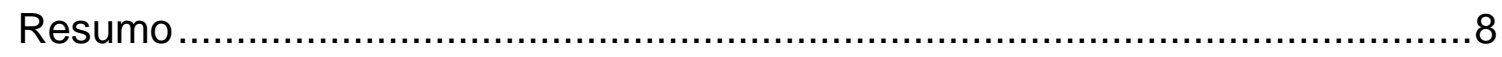

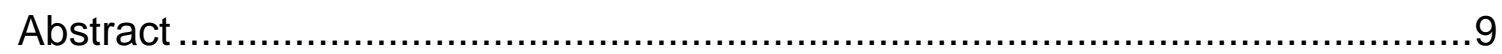

1. INTRODUÇÃO

2. ESTUDO 1: Efeitos do tipo de exercício nos parâmetros do andar de idosas.18

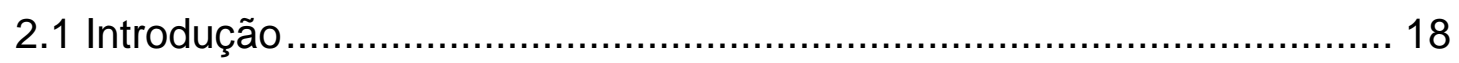

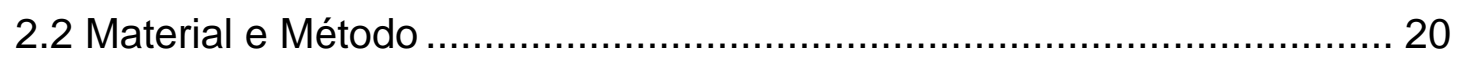

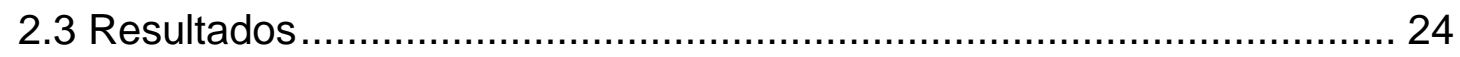

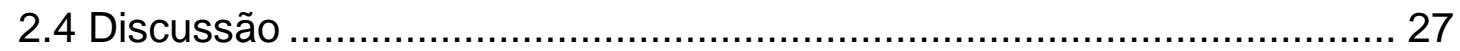

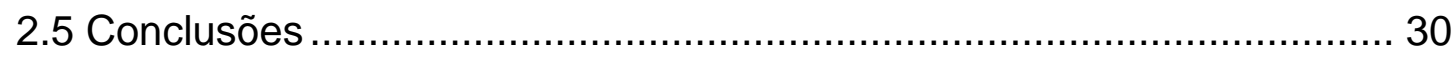

3. ESTUDO 2: Mudanças no padrão de andar, nas características antropométricas e na capacidade funcional de idosas após participação em programa de exercícios generalizados.........................................................31

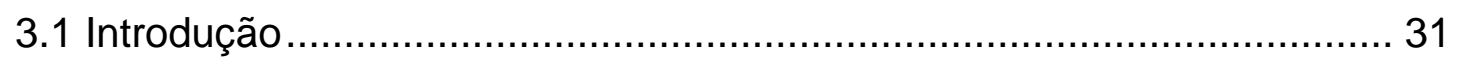

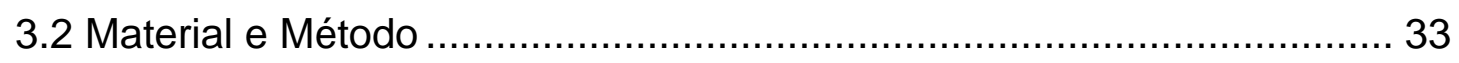

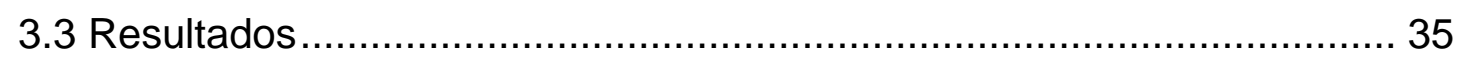

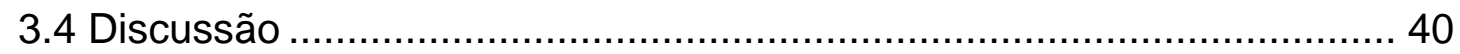

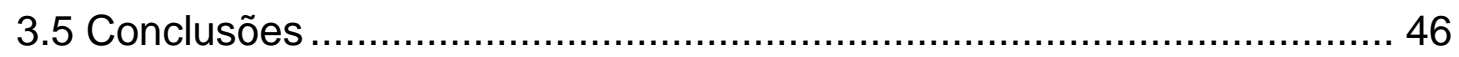

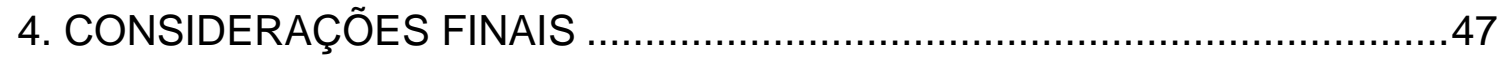

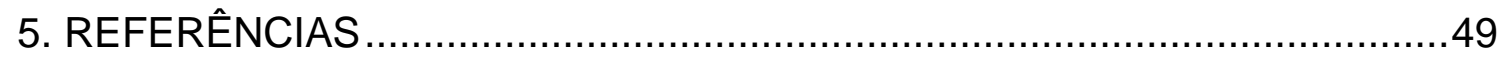

ANEXO 1a: Termo de consentimento livre e esclarecido - Estudo 1................60

ANEXO 1b: Termo de consentimento livre e esclarecido - Estudo 2................61

ANEXO 2: Ficha de Cadastro e Anamnese ……...........................................62

ANEXO 3: Tradução do questionário modificado de Baecke para idosos

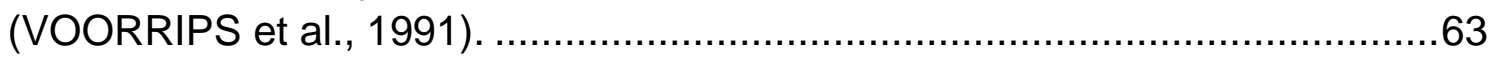

ANEXO 4: Percentis das variáveis antropométricas de IMC e DCT...................65

ANEXO 5: Avaliação da capacidade funcional: níveis de aptidão funcional (Osness et al., 1990). 


\section{LISTA DE FIGURAS}

Página

Figura 1. Médias e desvios-padrão da pontuação referente ao nível de

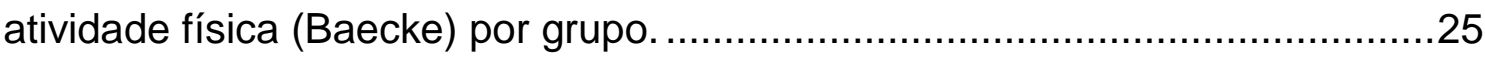

Figura 2. Médias e desvios-padrão do comprimento do passo (Cpass; a) e do comprimento da passada ( $\mathrm{Cp} ; \mathrm{b}) . \mathrm{O}$ * representa a diferença estatisticamente significante entre o grupo Controle e o grupo Dança. ......................................26

Figura 3. Representação das sequências empregadas para distribuição dos componentes da capacidade funcional entre as sessões.

Figura 4. Médias e desvios-padrão do nível de atividade física antes e após o treinamento nos componentes atividade física e escore geral no questionário de Baecke. .36 


\section{LISTA DE TABELAS}

Página

Tabela 1. Caracterização dos participantes ( $n=$ número de participantes, Idade, Estatura, Peso, IMC= índice de massa corporal, Dobra Cutânea do Tríceps, $\sigma=$ desvio-padrão).

Tabela 2. Médias e desvios-padrão $(\sigma)$ dos componentes da capacidade funcional por grupo.

Tabela 3. Médias e desvios-padrão das variáveis do andar por grupo $(\mathrm{Dp}=$ duração da passada; $\mathrm{Vp}=$ velocidade da passada; $\mathrm{Cad}=$ cadencia; $\mathrm{Dfbp}=$ duração da fase de balanço da passada; Dssp= duração do suporte simples da passada; Ddsp= duração do duplo suporte da passada).

Tabela 4. Variáveis preditoras do comprimento do passo, com os respectivos valores de Beta e significância.

Tabela 5. Variáveis preditoras do comprimento da passada, com os respectivos valores de Beta e significância.

Tabela 6. Caracterização dos participantes ( $n=$ número de participantes, estatura, peso, IMC= índice de massa corporal, idade, DCT= dobra cutânea triciptal, $\sigma=$ desvio-padrão), nos momentos pré e pós-intervenção.

Tabela 7. Médias e desvios-padrão $(\sigma)$ dos componentes da capacidade funcional pré e pós-intervenção, valor do teste de Wilcoxon (Z) e significância.36

Tabela 8. Médias, desvios-padrão ( $\sigma$ ), valor do teste de Wilcoxon $(Z)$ e significância das variáveis da marcha pré e pós-intervenção

Tabela 9. Variáveis preditoras da duração da passada pré e pós-intervenção, com os respectivos valores de Beta e significância.

Tabela 10. Variáveis preditoras da velocidade da passada pré e pósintervenção, com os respectivos valores de Beta e significância.

Tabela 11. Variáveis preditoras da Cadência pré e pós-intervenção, com os respectivos valores de Beta e significância.

Tabela 12. Variáveis preditoras da duração do suporte simples pré e pósintervenção, com os respectivos valores de Beta e significância.

Tabela 13. Variáveis preditoras da duração do duplo suporte pré e pósintervenção, com os respectivos valores de Beta e significância. 


\section{Resumo}

O padrão do andar sofre alterações com a idade devido a alguns fatores inerentes ao envelhecimento como diminuição da mobilidade, do equilíbrio e da capacidade funcional. O exercício físico se apresenta como uma alternativa capaz de reduzir estes efeitos e, consequentemente, produzir mudanças nos parâmetros do andar e na capacidade funcional, repercutindo em melhora na mobilidade e na independência funcional. As características do exercício, como tipo, frequência e intensidade, que podem melhor favorecer estas mudanças ainda não estão claramente definidas. Assim, o presente trabalho foi desenvolvido em dois estudos, com os seguintes objetivos: Estudo 1) comparar os efeitos de diferentes tipos de exercício nos parâmetros cinemáticos do andar de idosas, considerando as características antropométricas, a capacidade funcional e o nível de atividade física; e Estudo 2) avaliar os parâmetros do andar de idosas sedentárias antes e após o envolvimento em um programa de exercícios generalizados, considerando também as características antropométricas, a capacidade funcional e o nível de atividade física, conforme o Estudo 1. Participaram do Estudo 1, 56 idosas que foram agrupadas de acordo com o envolvimento, a mais de 6 meses, em: dança $(n=10)$, musculação $(n=10)$, hidroginástica $(n=12)$, caminhada $(n=11)$ e um grupo de idosas inativas $(n=13)$, sem envolvimento em exercício físico por pelo menos 02 meses. Participaram do Estudo 2, 32 mulheres acima de 60 anos, sedentárias, recrutadas em grupos de terceira idade, sendo que 17 delas atenderam aos critérios de inclusão. Para o Estudo 2, foi desenvolvido um Programa de Exercícios Generalizados (PEG) durante 4 meses, incluindo atividades de aquecimento, alongamento, dança, musculação e atividades recreativas, com ênfase nos componentes da capacidade funcional (resistência aeróbia, força muscular, coordenação motora, flexibilidade e equilíbrio corporal). Para os dois estudos, foram mensurados o nível de atividade física (Questionário de Baecke), a capacidade funcional (Bateria da AAHPERD) e os parâmetros cinemáticos do andar (comprimento da passada e do passo, duração e velocidade da passada, cadência e duração das fases de suporte simples, balanço e duplo suporte). Os resultados do Estudo 1 revelaram que o nível de atividade física do grupo controle foi diferente dos demais grupos que praticam atividades físicas. Em relação à capacidade funcional, apenas o componente força apresentou diferenças entre os grupos, indicando que o grupo controle difere do grupo musculação. Quanto às variáveis do andar, o grupo controle foi estatisticamente diferente apenas do grupo dança, tanto no comprimento do passo como no comprimento da passada. Os resultados do Estudo 2 mostraram que o PEG foi efetivo na redução da dobra cutânea tricipital, no aumento do nível de atividade física geral, na melhora de todos os componentes da capacidade funcional e dos parâmetros temporais do andar (duração e velocidade da passada, cadência, duração do suporte simples e duplo da passada). Em ambos os estudos, houve um forte relacionamento entre as variáveis temporais e espaciais do andar e as variáveis demográficas e estruturais. Estes resultados permitem concluir que o exercício generalizado, com controle da intensidade e frequência, foi mais efetivo em promover mudanças positivas no padrão de andar do que a prática de apenas um tipo de exercício.

Palavras-chave: Exercício; Envelhecimento; Andar; Cinemática; Capacidade Funcional. 


\section{Abstract \\ Title: Exercise effects on gait parameters of older women.}

Gait parameters change with age due to some inherent factors to the aging process such as reduced mobility, balance and functional capacity. The physical exercise is an alternative able to reduce these effects and, consequently, it produces changes in both the gait parameters and the functional capacities, improving mobility and functional independency. The exercise features such as type, frequency and intensity, which can better favor these changes, are not fully defined. Then, the present work was designed in two studies with the following objectives: Study 1) to compare the effects of the different exercise types on gait kinematic parameters of older women considering their anthropometric characteristics, functional capacity and physical activity level; and Study 2) to evaluate the gait parameters of inactive women before and after the enrollment in a multi-mode exercise program also considering their anthropometric characteristics, functional capacity and physical activity level as in Study 1. Fifty-six older women participated in Study 1 and were grouped according to the exercise type enrollment for more than 6 months in dance $(n=10)$, strength training $(n=10)$, hydrogymnastic $(n=12)$, walking $(n=11)$ and a group of inactive women $(n=13)$, without enrollment in physical exercise for at least two months. Thirty-two women, older than 60 years, inactives, from elderly groups were recruited to participate in Study 2. Seventeen women full filled the inclusion criteria. For Study 2, a Generalized Exercise Program (GEP) was developed in 4 months, including warm up activities, dance, strength training, and recreational activities emphasizing the components of the functional capacity (aerobic endurance, strength, coordination, flexibility, and body balance). For both studies, the physical activity level (Baecke questionnaire), the functional capacity (AAHPERD test battery) and the kinematic gait parameters (stride and step lengths, stride duration and velocity, cadence, and percentage of time in single support, double support and swing phases) were measured. The Study 1 results revealed that the physical activity level of the inactive group was different of all other groups. For the functional capacity, only the muscular strength was different within groups, with the strength training presenting better results than the inactive group. For the gait parameters, the inactive group were different only for the dance group in the stride and step length. The Study 2 results revealed that the GEP was effective in reducing the triceps skinfold, in increasing the general physical activity level; and in improving both all the functional capacity components and the temporal gait parameters (stride velocity and duration, cadence, percentage time in single and double support). In both studies, there was a strong association among the temporal and spatial gait parameters and the demographic and structural variables. These results drive the conclusion that the generalized exercise, with the control intensity and frequency, was more effective in promoting positive changes in the gait parameters than the practice of only one exercise type.

Key-words: Exercise; Aging; Gait; Kinematics; Functional Capacity. 


\section{INTRODUÇÃO}

Em 2008, o IBGE estimou que o Brasil terá cerca de 17 milhões de idosos em 2010. Projeções da Organização Mundial da Saúde indicam que o Brasil terá 32 milhões de idosos entre 2020 e 2025 e será o sexto país do mundo em número de idosos (INSTITUTO DE CARDIOLOGIA DO RIO GRANDE DO SUL, 2006). A população de indivíduos idosos representava um contingente de aproximadamente 15 milhões de pessoas com mais de 60 anos em 2008 (IBGE, 2008). Deste total, as mulheres são maioria, representando 8,9 milhões ou $62,4 \%$.

O limite de idade entre o indivíduo adulto e o idoso é de 65 anos para as nações desenvolvidas e de 60 anos para os países em desenvolvimento (FREITAS; PY; NERI, 2002). O processo de envelhecimento inicia com o nascimento e, aproximadamente, ao final da segunda década de vida começa a ocorrer o declínio funcional dos órgãos, que se apresenta de forma linear em função do tempo (GUCCIONE, 2002; DOUGLAS 2002). Ainda que não se possa definir um ponto exato dessa transição, assim como algumas outras fases da maturação humana, as alterações anatomofuncionais atribuídas ao envelhecimento evidenciam-se ao final da terceira década (BASSETTO et al., 2008).

A velhice é um fenômeno histórico, social, cultural, multifacetado e de interesse multidisciplinar. $O$ processo de envelhecimento não se resume aos aspectos demográficos, pois sua complexidade exige que seja estudado por diversas áreas, sob múltiplos ângulos. Este processo percorre toda a história da humanidade, mas apresenta características diferenciadas de acordo com a cultura, com o tempo e com o espaço (PY et al., 2004). 
No processo natural de envelhecimento acontece diminuição na capacidade funcional do organismo como um todo e, como consequência, aparecem as doenças crônico-degenerativas que levam a incapacidades. Esta queda na capacidade funcional dos idosos pode ser acelerada ou adiada por fatores genéticos, pelo estilo de vida e pelo ambiente em que se vive (MAZO et al., 2004). Este processo é caracterizado por uma sequência de eventos que trazem perda funcional progressiva, diminuindo a capacidade de restabelecer a homeostase, inicialmente diante de um estresse e, posteriormente, mesmo sob condições basais (LIBERMAN; CUKIERT, 2004).

Dentre os efeitos deletérios do envelhecimento estão o enfraquecimento do tônus muscular e da constituição óssea. Esses levam a mudanças na postura do tronco e das pernas, acentuando ainda mais as curvaturas da coluna torácica e lombar. As articulações tornam-se mais endurecidas, reduzindo assim a amplitude dos movimentos e produzindo alterações no equilíbrio e na marcha (MARCHI NETTO, 2004).

Ainda, em relação aos aspectos antropométricos, o peso e a estatura tendem a diminuir acompanhando o envelhecimento. A redução do peso corporal é devida à diminuição da massa magra e à modificação no padrão de gordura corporal, onde o tecido gorduroso dos braços e das pernas diminui, mas aumenta no tronco (MENEZES; MARUCCI, 2005). O excesso de peso é um dos fatores determinantes no aparecimento da osteoartrite; enquanto que a diminuição de massa muscular provoca a perda progressiva de força, afetando a deambulação (PAPALÉO NETO, 2002).

A redução da massa muscular magra se dá pela diminuição no número e no tamanho das fibras, sendo que as de contração rápida são mais prejudicadas. A força possui importantes implicações para a massa óssea, bem como no padrão morfofuncional do sistema de locomoção dos idosos, no equilíbrio e no risco de quedas, revelando-se uma capacidade física de fundamental importância para a qualidade de vida dos idosos (SHEPHARD, 2003). Como consequência, ocorre redução no envolvimento em atividades físicas.

A capacidade funcional ou aptidão funcional pode ser definida como o potencial que os idosos apresentam em realizar as tarefas do seu cotidiano de forma independente (MATSUDO, 2000; SANCHEZ, 2000; DUAYER et al., 
2007). Na prática, trabalha-se com o conceito de capacidade/incapacidade devido aos diferentes fatores que indicam a complexidade da capacidade funcional, daí a importância de seu preciso entendimento (ROSA et al., 2003). Ainda, a capacidade funcional é vista como um novo componente no modelo de saúde de idosos (RAMOS, 2003).

A capacidade que os idosos tem de manter-se independentes parece estar associada, em grande parte, à manutenção dos níveis de flexibilidade, força e resistência musculares, características consideradas como componentes da aptidão física (PENDERGAST et al., 1993; KELL et al., 2001). Um exemplo da influência desses componentes sobre a aptidão física e funcional no envelhecimento diz respeito à alteração no padrão do andar.

A avaliação da aptidão funcional é essencial para identificar o nível de seus componentes específicos e, consequentemente, desenvolver um programa de atividade física (BENEDETTI et al., 2007). O desenvolvimento de atividades voltadas ao idoso tem como objetivo principal a autonomia e o desempenho nas atividades do cotidiano, principalmente as que requerem 0 andar.

Baseado na importância de se avaliar a capacidade funcional global, a American Alliance for Health, Physical Education, Recreation and Dance (AAHPERD) desenvolveu uma bateria de testes específica para medir a aptidão funcional em idosos. Esta bateria é composta de cinco testes motores: agilidade e equilíbrio dinâmico, coordenação, resistência de força, flexibilidade e resistência aeróbia geral (OSNESS, 1990). Zago e Gobbi (2003) e Benedetti et al. (2007) desenvolveram valores normativos para a bateria da AAHPERD, de forma que é possível obter o índice de aptidão funcional geral em idosas de 60 a 70 anos e de 70 a 79 anos, respectivamente.

A agilidade e o equilíbrio dinâmico são requisitados na realização de movimentos corporais rápidos como desviar-se de pessoas e andar rapidamente pela casa (ZAGO; GOBBI, 2003; BENEDETTI et al., 2007). A coordenação é a base para o aprendizado sensório-motor, pois facilita a aquisição e correção de movimentos novos e automatizados (BENEDETTI et al., 2007) e a realização de movimentos rítmicos. A resistência de força permite a movimentação do corpo através da contração muscular, possibilitando a realização de tarefas como varrer e carregar objetos (ZAGO; GOBBI, 2003). A 
flexibilidade é a amplitude dos movimentos articulares, sendo fundamental para atividades como andar e amarrar os sapatos (ZAGO; GOBBI, 2003). A resistência aeróbia geral é a capacidade de captação e utilização de oxigênio durante a atividade e o maior ou menor grau de diminuição depende do envolvimento em atividades físicas (ZAGO; GOBBI, 2003; BENEDETTI et al., 2007).

A capacidade funcional, especialmente a dimensão física, é um dos importantes marcadores de um envelhecimento bem sucedido e da qualidade de vida dos idosos (CIPRIANI et al., 2010). A perda dessa capacidade está associada a problemas de mobilidade e à predição de fragilidade, dependência, institucionalização, risco aumentado de quedas e morte. A perda da capacidade funcional traz complicações ao longo do tempo e gera cuidados de longa permanência e de alto custo (CORDEIRO et al., 2002).

A diminuição funcional e a redução na qualidade de vida do idoso são atribuídas a três fatores: envelhecimento normal, doenças e inatividade (NAHAS, 2001). O sedentarismo é o estilo de vida que traz os maiores problemas para o envelhecimento. A atividade física é considerada como toda e qualquer ação que proporcione contração muscular e, diferentemente, o exercício físico é definido como uma ação planejada e com objetivo específico, que busque melhorar ou manter um ou mais componentes da aptidão física relacionada à saúde (CASPERSEN et al.; 1985; MATSUDO et al., 2001).

A prática de atividade física é uma das principais formas de evitar, minimizar e ou reverter muitos dos declínios físicos, psicológicos e sociais que comumente acompanham a idade avançada. Existem fortes evidências da associação entre a prática de atividade física e melhoras significativas nas condições de saúde como o controle do estresse, obesidade, diabetes, doenças coronarianas e, principalmente, na aptidão funcional do idoso (GOBBI, 1997). Gobbi \& Ansarah (1992) também comprovaram a melhora dos componentes da capacidade funcional em indivíduos idosos, relatando que praticantes de atividade física de forma regular tendem a apresentar melhor aptidão funcional e, consequentemente, maior autonomia.

O exercício físico tem indiscutível importância para esta população, uma vez que possibilita a retomada da independência física, além de facilitar as relações entre participantes. Neste aspecto, os exercícios em grupo são os 
mais interessantes e indicados, pois há considerável melhora nas relações sociais, na saúde física e psicológica. Esses benefícios colaboram para retardar o processo de envelhecimento e proporcionam uma velhice mais autônoma e independente. Desta forma, há elevação na qualidade de vida e diminuição na incidência de doenças crônico-degenerativas. O exercício regular tem a capacidade de reduzir a idade biológica em 10 a 20 anos (SHEPHARD, 2003).

Nahas (2001) apresenta uma série de benefícios da prática regular de exercícios físicos: promove melhora fisiológica (no controle da glicose, na qualidade de sono, nas capacidades físicas relacionadas à saúde), psicológica (no relaxamento, na redução dos níveis de ansiedade e estresse, no estado de espírito, na cognição), social (na integração social e cultural) e na saúde (na redução ou prevenção de doenças como a osteoporose e os desvios posturais). Pesquisas apontam também para melhora na consciência corporal, aumento do bem-estar físico e psicológico, diminuição dos níveis de estresse e consequente redução dos estados depressivos (STUNKARD et al., 2003).

O papel do exercício na melhora da condição geral do indivíduo idoso tem sido evidenciado (MOREIRA, 2001; MATSUDO, 2002; RADOM-AIZIK et al., 2005). Assim, diferentes tipos de exercícios estão sendo oferecidos aos idosos, no sentido de verificar qual promove maiores benefícios, entre eles a hidroginástica, a ginástica, a musculação e a caminhada (SOARES et al., 2003; CARVALHO-ALVES; MEDEIROS, 2004; MEANS et al., 2005), ficando a cargo do idoso escolher a que melhor se adapte (SANTOS; PEREIRA, 2006).

As implicações do envelhecimento relacionadas à aptidão física, que é capacidade de desempenhar atividades profissionais, recreativas e da vida diária sem fadigar em excesso (HEYWARD, 2004), têm sido amplamente estudadas. No entanto, estudar a capacidade funcional de idosos vem se tornando um instrumento bastante utilizado para melhor compreender o estado de saúde dos idosos e, principalmente, o grau de autonomia para execução de tarefas do cotidiano, como o andar. Existe uma estreita relação entre a manutenção da mobilidade e o nível de independência funcional das pessoas idosas. As modificações no padrão de andar em idosos são multifatoriais, tornando tal fenômeno difícil de ser explicado (FARINATTI; LOPES, 2004). 
O andar é uma habilidade locomotora fundamental, que é automatizada aproximadamente aos sete anos de idade (VIEL, 2001) e que continua relativamente estável por quase toda a vida (WINTER, 1991). O andar se destaca por participar nas mais diversas formas do movimento humano (AMADIO, 1996). Ele envolve distintos padrões de movimentos estabelecidos por complexas estruturas neurológicas sincronizadas com as demais funções do aparelho locomotor humano. Ainda, o andar é uma habilidade motora extremamente complexa, composta por uma sequência de movimentos cíclicos dos membros inferiores, que geram o deslocamento do corpo. Durante sua execução, há sucessivos momentos de instabilidade ocasionados pela transferência de peso de um pé para o outro (SPIRDUSO, 1995). Manter a projeção do centro de gravidade continuamente entre os dois pés garante um deslocamento estável (MASSION, 1992).

Dois eventos principais são identificados durante a execução do andar: o passo e a passada. O passo, que compreende o tempo entre 0 toque de um calcanhar no solo até o toque do calcanhar oposto (WAGENAAR; VAN EMMERIK, 2000), podendo ser subdividido em dois momentos: a fase de apoio (ou de suporte) e a fase de balanço. Durante a fase de apoio, são geradas forças horizontais contra o solo que resultam no deslocamento do corpo à frente e forças verticais que suportam a massa corporal contra a gravidade. A fase de balanço inclui a progressão à frente de um dos membros, o contato do pé com o solo e a preparação para a recepção de carga. A cada passo, a projeção do centro de gravidade é deslocada para frente do tronco e a perna de apoio fornece suporte corporal, até que a perna de balanço faça contato com o solo em um local que permita o ajuste adequado do equilíbrio, até o próximo ciclo (WINTER, 1995).

A ocorrência de dois passos compõe um ciclo de passada, que é definido como o intervalo entre dois contatos do mesmo pé com o solo (SAAD; BATISTELLA, 1997; SHUMWAY-COOK; WOOLLACOTT, 1995). São componentes de um ciclo de passada:

- Duplo apoio: período em que os dois pés se mantêm em contato com o solo, embora nenhum deles permaneça com a planta completamente apoiada. Enquanto um dos membros recebe a carga total do corpo, o outro se prepara para impulsioná-lo à frente. $\mathrm{O}$ duplo apoio subdivide-se em outras duas 
fases: contato inicial e recepção ou resposta à carga, que tem a função de desacelerar o deslocamento do centro de gravidade e minimizar o choque do pé com o solo; e a fase de propulsão, caracterizada pela ação muscular impulsionando o corpo para frente, enquanto o calcanhar está elevado. A fase de duplo apoio é considerada o período que possibilita melhor equilíbrio durante a marcha (WINTER et al., 1990);

- Apoio simples: inicia-se com a perda de contato de um dos pés com o solo e corresponde ao período em que o membro oposto está em fase de balanço. Durante esta fase, apenas um dos pés é mantido em contato com o solo, enquanto o membro oposto é deslocado à frente. Suas funções são a progressão do corpo e a estabilização do tronco sobre o membro apoiado;

- Balanço: inicia quando um dos pés perde o contato com o solo e é dividido em "balanço inicial" (perda de contato do pé com o solo), "balanço médio" (avanço do membro inferior) e "balanço terminal" (o membro inferior completa o avanço e é preparado para o apoio). Uma das variáveis mais importantes relacionadas ao controle motor durante esta fase é o avanço do membro para frente, que é determinado pela combinação entre a velocidade de deslocamento da perna e comprimento do passo.

Entretanto, estudos têm mostrado que o padrão de andar em idosos difere do padrão encontrado em adultos jovens (VIEL, 2001; WINTER, 1991; PRINCE et al., 1997). Acredita-se que tais diferenças estejam relacionadas à perda progressiva da amplitude das articulações, que ocorre principalmente pela degradação dos tecidos conjuntivos periarticulares (PRINCE et al., 1997), e pela redução da massa muscular (PAPALÉO NETO, 2002; SHEPHARD, 2003).

Análises cinemáticas e cinéticas têm sido utilizadas como ferramentas para melhor compreensão das características dos padrões de andar (DAVID, 2000). A cinemática vem auxiliando na descrição de características como deslocamento, velocidade $\mathrm{e}$ ângulos articulares. $\mathrm{O}$ andar tem sido cinematicamente descrito pelas variáveis espaciais e temporais: cadência, tempo de duplo apoio e apoio simples, comprimento e largura do passo e da passada, duração e velocidade, entre outros. Esta ferramenta tem evidenciado diminuição no comprimento da passada e do passo, diminuição da distância entre o pé e o solo na fase de balanço, aumento na duração da passada e 
aumento no tempo em duplo suporte (WILLIAMS; BIRD, 1992; PRINCE et al., 1997; LAUFER, 2005; MILLS et al., 2008).

Desta forma, este estudo buscou analisar o padrão de andar de idosas de acordo com o envolvimento em: a) diferentes tipos de exercício, considerando as características antropométricas, a capacidade funcional e o nível de atividade física; e b) um programa de exercícios generalizados. Para isso, o trabalho foi desdobrado em dois estudos. Espera-se que os resultados do Estudo 1 permitam tanto observar os benefícios do exercício para o andar, como recomendar a prática regular de um ou mais tipos de exercício para idosas. No e

Estudo 2, espera-se que após a participação no programa, as idosas tenham melhorado as características antropométricas (diminuição da massa gorda) e a capacidade funcional e reduzido os efeitos do envelhecimento e do sedentarismo nos parâmetros do andar. 


\section{ESTUDO 1: Efeitos do tipo de exercício nos parâmetros do andar de}

idosas.

\subsection{Introdução}

Manter-se ativo na terceira idade tem sido uma estratégia bastante utilizada para o desenvolvimento e melhora nos padrões de saúde e na qualidade de vida desta população (FERREIRA et al., 2005). Já é possível observar na literatura uma concordância de que o exercício é um fator de grande importância para a manutenção da saúde, do nível de capacidade funcional de indivíduos idosos e até da redução da taxa de declínio que o envelhecimento ocasiona (SEBASTIÃO et al., 2005; MATSUDO et al., 2001; MAZO et al., 2005).

O processo de envelhecimento causa modificações nas estruturas articulares e periarticulares, que se tornam menos flexíveis em decorrência de pequenas alterações morfológicas, anatômicas e bioquímicas. Essas mudanças podem provocar perda de estabilidade na biomecânica do andar, que é um importante componente do desempenho motor (JACOB FILHO; ISHIZUCA, 2004).

O andar integra a maioria das atividades básicas e instrumentais da vida diária a ponto de ser recomendado como uma forma de exercício para prevenção de quedas em idosos (WHO, 2007). Por outro lado, os parâmetros de andar são modificados durante o processo de envelhecimento ocorrendo diminuição da velocidade da marcha, pelo maior tempo gasto na fase de duplo apoio e pela diminuição do comprimento da passada. Além disso, o aumento do tempo de duplo apoio pode se refletir sobre o controle motor corporal durante o apoio simples (ROSE; GAMBLE, 2006). Frontera e Xavier (2002) 
apontam que as alterações normalmente encontradas na marcha dos idosos estão associadas à redução da força muscular decorrente do processo de envelhecimento. E a diminuição da força muscular leva os idosos a utilizarem um percentual maior de contração muscular durante a marcha.

A prática de exercício tende a reduzir os efeitos do processo de envelhecimento, tanto em relação às capacidades funcionais (SHEPHARD, 2003; GOBBI et al., 2005; SIMONSICK et al., 2006) como em relação à mobilidade funcional em idosos sadios (BRACH et al., 2004; SHUMWAYCOOK et al., 2005; NITZ; HOURIGAN, 2006), manter a independência de idosos sadios nas várias atividades em que são solicitados ao longo de seu cotidiano (STESSMAN et al., 2002), em idosos com comprometimentos (GUIMARÃES et al., 2004) e em idosos institucionalizados (BOYLE et al., 2007).

Apesar da variedade de exercícios proposta aos idosos, não existe consenso de qual delas seria mais apropriada (SOARES et al., 2003; CARVALHO-ALVES; MEDEIROS, 2004; MEANS et al., 2005). Exercícios como caminhada e dança são bastante apreciados pelos idosos, além de promoverem melhora no sistema cardiovascular e, quando associados a exercícios resistidos, promovem também aumento da massa muscular e melhora no equilíbrio (NAHAS, 2001). Os efeitos da dança em longo prazo influenciam positivamente as características do andar e do equilíbrio (VERGHESE, 2006).

Os exercícios de musculação são bastante eficazes, uma vez que melhoram a força muscular, estimulando o aumento da massa óssea, evitando, assim, as tão temidas fraturas por quedas. Essa melhora na força também é um fator de incremento da autonomia, uma vez que o idoso consegue realizar suas tarefas diárias com mais facilidade (ANTONIAZZI; DIAS, 2002).

A prática regular de musculação e de hidroginástica por idosas reduz a sarcopenia (diminuição da função da musculatura esquelética), induzida pelo envelhecimento, e aumenta a qualidade da marcha, reduz o risco de quedas e adiciona eficiência na realização de atividades da vida diária (SANTOS; PEREIRA, 2006). Barbosa et al. (2000) relatam que a utilização de um programa de treinamento resistido é segura e eficaz para aumentar a força muscular de mulheres idosas. 
A hidroginástica é bastante eficiente nos casos de pessoas que sofrem com problemas articulares, pois nesta modalidade o impacto nos membros inferiores é sensivelmente diminuído. Resistência aeróbia, força e flexibilidade podem ser trabalhadas no ambiente aquático, por oferecer como vantagens a flutuação, a resistência e a pressão hidrostática, além de possibilitar trabalhos com maiores amplitudes articulares (ALMEIDA et al, 2010). Os exercícios próprios da hidroginástica são mais fáceis de realizar e menos dolorosos, além de promover a interação social que tanto é importante ao idoso. As atividades aquáticas são excelentes para as articulações e para os músculos (FERREIRA, 2003).

Diante do exposto, o objetivo deste estudo foi comparar os efeitos de diferentes tipos de exercício nos parâmetros cinemáticos do andar de idosas, considerando as características antropométricas, a capacidade funcional e o nível de atividade física.

\subsection{Material e Método}

Este estudo foi submetido e aprovado pelo Comitê de Ética em Pesquisa da Universidade Estadual da Paraíba (protocolo número CAAE 0450.0.133.000-08). Todas as informações sobre a pesquisa foram dadas aos participantes e um termo de consentimento livre e esclarecido para participação no estudo foi preenchido e assinado por estes (Anexo 1).

Foi realizada uma pesquisa do tipo descritiva transversal.

\section{Participantes}

Mulheres de 60 anos ou mais foram recrutadas intencionalmente em programas de exercício da cidade de Campina Grande - PB. As idosas foram agrupadas de acordo com o envolvimento em um tipo de exercício específico (dança, musculação, hidroginástica e caminhada). Além disso, um grupo de idosas inativas (controle) também foi recrutado em grupos de terceira idade. Os critérios de inclusão para os grupos de idosas ativas foram: ter 60 anos ou mais, envolvimento no tipo de específico de exercício por, pelo menos, 6 meses. 
O grupo controle foi formado com os seguintes critérios de inclusão: enquadrar-se no $1^{0}$ tercil do nível de atividade física (menos ativa), não envolvimento em exercício regular por pelo menos 02 meses.

Os critérios de exclusão foram os mesmos para os grupos: história ou caso de infarto do miocárdio, angina pectoris e/ou insuficiência cardíaca; diabetes mellitus do tipo 1 , insulina-dependente; problemas ósteo-mioarticulares que dificultem a locomoção; e uso regular de medicamentos que interferem no equilíbrio, onde uma anamnese foi empregada (Anexo 2).

Para avaliar o nível de atividade física dos participantes foi utilizado o Questionário Baecke Modificado para Idosos (QBMI - VOORRIPS et al., 1991; Anexo 3). Este questionário é composto por 3 partes: atividades domésticas, esportivas e de lazer. A pontuação das atividades domésticas é obtida pela soma da pontuação nestas questões dividida pelo número total de questões. Já os escores para as atividades esportivas e de lazer consideram a intensidade da atividade, horas da atividade realizada por semana e meses por ano. A classificação do nível de atividade física foi distribuída em tercis e, desta forma, escores menores representam menor nível de atividade física $\left(1^{\circ}\right.$ tercil $=$ menos ativa; $2^{\circ}$ tercil $=$ moderadamente ativa e $3^{\circ}$ tercil $=$ ativo).

\section{Procedimentos}

Após a assinatura do termo de consentimento livre e esclarecido, foi realizada a Avaliação Antropométrica, nos seguintes aspectos: estatura e massa corporal para obtenção do índice de massa corporal (IMC); e dobra cutânea tricipital (DCT) para percentual de gordura. O IMC foi determinado através da divisão da massa corporal total, expressa em quilograma $(\mathrm{kg})$, pela estatura, expressa em metro $(\mathrm{m})$ ao quadrado. A técnica de medidas adotadas foi a sugerida por Lohman et al. (1988). Apesar do IMC ser um método internacionalmente aceito para classificação do estado nutricional, não distingue a massa adiposa da massa livre de gordura (NUNES et al, 2009). Por isso foi adotado neste estudo, dois métodos de análises.

Para a mensuração do peso utilizou-se balança eletrônica digital portátil, marca TANITA, com capacidade para $150 \mathrm{~kg}$ e sensibilidade de $100 \mathrm{~g}$. A dobra cutânea tricipital (DCT) foi mensurada utilizando o compasso Lange com precisão de $1 \mathrm{~mm}$. 
Para a avaliação dos parâmetros antropométricos as idosas foram agrupadas segundo grupo etário (60-69 anos, 70-79 anos e 80 anos e mais). Estas variáveis antropométricas foram classificadas e apresentadas em percentil (P5, P10, P25, P50, P75, P90 e P95) de acordo Menezes e Marucci, (2005). Entretanto, para o estudo desta tese, a classificação foi agrupada em cinco categorias: $P 5=$ desnutrição; $P>5<25=$ risco a desnutrição; $P>25<$ 75 = peso adequado; $\mathrm{P}>75<95=$ excesso de peso e $\mathrm{P}>95=$ obesidade, como pode ser visto no (Anexo 4).

Para a análise dos dados antropométricos coletados foi utilizado software de avaliação física desenvolvido pela firma BIO-SYSTEM de Campina Grande - PB, constando de banco de dados para gerenciamento das fichas e realização de todos os procedimentos de cálculos e fórmulas envolvidas, programadas em linguagem Pascal - Delphi.

Os níveis de capacidade funcional foram avaliados por meio dos testes motores de agilidade e equilíbrio dinâmico, coordenação, resistência de força, flexibilidade e resistência aeróbia geral, propostos pela AAHPERD (Anexo 5).

Para avaliação do andar, cada participante foi convidada a percorrer andando uma distância de 8 metros. Após o comando do pesquisador, a participante andou, na sua velocidade preferida, até o final da passarela, em 10 tentativas. Intervalos de descanso foram fornecidos sempre que solicitado pela participante. Para registro dos dados cinemáticos, oito marcadores passivos, feitos de película refletiva adesiva de 15 milímetros de diâmetro, foram afixados nos seguintes pontos anatômicos: a) trocanter maior do fêmur; b) côndilo lateral da tíbia; c) maléolo fibular direito; d) maléolo tibial esquerdo; e) face lateral do calcâneo direito; f) face medial do calcâneo esquerdo; g) face lateral da cabeça do $5^{\circ}$ metatarso direito; e h) face medial da cabeça do $1^{\circ}$ metatarso esquerdo. Uma filmadora digital (marca Samsung, SDC173U) foi posicionada perpendicularmente ao centro da distância percorrida para filmar o plano sagital direito das participantes, de modo a visualizar todos os marcadores e registrar uma passada intermediária do percurso do membro inferior direito. A frequência de aquisição das imagens era de $60 \mathrm{~Hz}$.

As imagens registradas foram capturadas por uma placa de vídeo (marca PINNACLE, modelo Studio DV, versão 1.05.307) acoplada a um computador. Das 10 tentativas de cada participante, 5 foram selecionadas para 
análise, sendo adotados os seguintes critérios: exclusão das duas primeiras e das duas últimas, nitidez da imagem e maior aproximação à área ortogonal de filmagem. Na sequência, os marcadores foram digitalizados automaticamente em uma passada do andar (intervalo entre dois contatos iniciais consecutivos do pé direito), com a utilização do programa Digital Vídeo for Windows DVIDEOW (Laboratório de Instrumentação em Biomecânica - Unicamp; BARROS et. al., 1999).

Após a digitalização, e ainda utilizando o programa DVIDEOW, as coordenadas $\mathrm{x}$ e y de cada marcador foram transformadas ao sistema métrico utilizando um sistema de referência bi-dimensional com 4 pontos de controle e com dimensões de $1 \mathrm{~m} \times 1 \mathrm{~m}$, comprimento e altura, respectivamente. $\mathrm{Na}$ sequência, os dados adquiridos foram filtrados com o filtro Butterworth de $2^{\text {a }}$ ordem, com a utilização do programa Matlab 6.5 (The Mathworks, Inc.). A frequência do filtro foi definida por meio de análises residuais sugeridas por Winter (1990).

As variáveis dependentes da marcha consideradas neste estudo foram: comprimento da passada $(m)$, comprimento do passo $(m)$, duração da passada (s), velocidade da passada (m/s), cadência (pass/s) e duração das fases de suporte simples, balanço e duplo suporte na passada (\%). Para a análise das variáveis foi utilizado o software Matlab 6.5.

\section{Análise Estatística}

Inicialmente, foram verificadas a distribuição dos dados de cada variável (teste de Kolmogorov-Smirnov) e a homogeneidade das variâncias (teste de Levene). Os dados indicaram que as variáveis nível de atividade física (pontuação no Questionário de Baecke) e coordenação (AAHPERD) não atenderam estes critérios. O nível de atividade física (Baecke) e os valores do teste de coordenação foram tratados pela estatística não paramétrica por meio de teste de Kruskal-Wallis e, para localizar possíveis diferenças entre os grupos, foi empregado o teste $U$ de Mann-Whitney, com nível de significância corrigido pelo número de comparações em $p<0,005$.

Para cada uma das demais variáveis dependentes, Análises de Variância (ANOVA), tendo grupo como único fator, foram realizadas. Foi 
realizado o teste de Tukey para localizar as possíveis diferenças reveladas pela ANOVA. Análises de Regressão Múltipla (stepwise) foram empregadas para verificar, dentre as variáveis relacionadas ao nível de atividade física, à capacidade funcional e às características antropométricas, quais foram preditoras do comprimento da passada e do passo. Os dados coletados receberam tratamento estatístico através de sistema computacional SPSS 13.0 for Windows. O nível de significância de $p<0,05$ foi considerado em todas as análises paramétricas.

\subsection{Resultados}

A população deste estudo compreendeu 56 idosas, que apresentaram as seguintes características: idade (68 \pm 6 anos), estatura $(1,51 \pm 0,06 \mathrm{~m})$, peso corporal $(65,42 \pm 11,38 \mathrm{~kg})$, índice de massa corporal $(29 \pm 5$ peso/altura $\left.{ }^{2}\right)$ e dobra cutânea triciptal $(21,33 \pm 5,55 \mathrm{~mm})$.

A Tabela 1 apresenta a caracterização antropométrica dos participantes por grupo. ANOVAs tendo grupo como fator único revelaram que os grupos são estatisticamente similares nas variáveis idade (anos), estatura $(\mathrm{m})$, peso $(\mathrm{Kg})$, IMC (peso/altura2) e dobra cutânea do tríceps ( $\mathrm{mm}$ ).

Tabela 1. Caracterização dos participantes ( $n=$ número de participantes, Idade, Estatura, Peso, IMC= índice de massa corporal, Dobra Cutânea do Tríceps, $\sigma=$ desvio-padrão).

\begin{tabular}{lcccccccccc}
\hline \hline \multirow{2}{*}{ Grupo } & \multicolumn{2}{c}{ Idade(anos) } & \multicolumn{2}{c}{ Estatura(m) } & \multicolumn{2}{c}{ Peso(kg) } & \multicolumn{2}{c}{ IMC } & \multicolumn{2}{c}{ DCT(mm) } \\
\cline { 2 - 10 } & Média & $\boldsymbol{\sigma}$ & Média & $\boldsymbol{\sigma}$ & Média & $\boldsymbol{\sigma}$ & Média & $\boldsymbol{\sigma}$ & Média & $\boldsymbol{\sigma}$ \\
\hline Controle $(\mathrm{n}=13)$ & 68,85 & 4,22 & 1,48 & 0,06 & 63,63 & 10,86 & 29,10 & 4,31 & 19,31 & 6,65 \\
Musculação $(\mathrm{n}=10)$ & 67,20 & 5,20 & 1,53 & 0,08 & 63,83 & 8,63 & 27,55 & 4,13 & 21,50 & 4,22 \\
Caminhada $(\mathrm{n}=11)$ & 66,83 & 5,65 & 1,50 & 0,04 & 63,03 & 9,70 & 28,06 & 3,86 & 24,27 & 5,10 \\
Hidroginástica $(\mathrm{n}=12)$ & 70,73 & 5,97 & 1,51 & 0,04 & 65,33 & 12,83 & 28,46 & 5,29 & 21,67 & 4,64 \\
Dança $(\mathrm{n}=10)$ & 69,80 & 7,27 & 1,54 & 0,05 & 72,29 & 13,95 & 30,53 & 6,29 & 20,20 & 6,20 \\
\hline
\end{tabular}

O teste de Kruskal-Wallis revelou que os grupos são diferentes quanto ao nível de atividade física $\left(X^{2}{ }_{4}=33,567 ; p<0,001\right)$. $O$ teste $U$ de Mann-Whitney revelou que o grupo controle é diferente estatisticamente dos demais grupos (Figura 1), que são iguais entre si (Controle $x$ Musculação: $Z=-4,045, p<0,001$; Controle $\times$ Caminhada: $Z=-4,255, p<0,001$; Controle $\times$ Hidroginástica: $Z=-4,156$, $p<0,001$; Controle $x$ Dança: $Z=-3,984, p<0,001)$. 


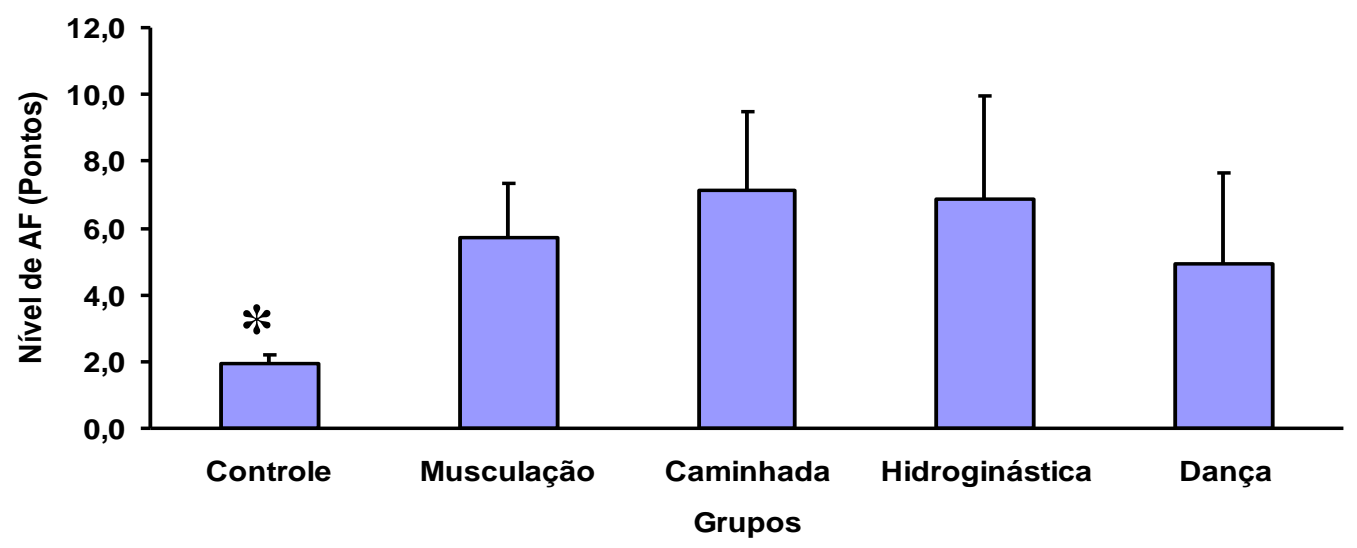

Figura 1. Médias e desvios-padrão da pontuação referente ao nível de atividade física (Baecke) por grupo.

Os níveis de capacidade funcional, separadamente por componente Flexibilidade (cm), Coordenação (s), Agilidade (s), Força (no rep) e Resistência (min) e por grupo, são apresentados na Tabela 2. A ANOVA revelou que apenas o componente força apresentou diferenças entre os grupos $\left(F_{4,51}=\right.$ 2,546; $p<0,05)$, sendo que $o$ teste post hoc de Tukey indicou que apenas 0 grupo Controle difere do grupo Musculação $(p<0,025)$.

Tabela 2. Médias e desvios-padrão $(\sigma)$ dos componentes da capacidade funcional por grupo.

\begin{tabular}{lrrrrrrrrrr}
\hline \hline \multirow{2}{*}{ Grupo } & \multicolumn{2}{c}{ Flexibilidade } & \multicolumn{2}{c}{ Coordenação } & \multicolumn{2}{c}{ Agilidade } & \multicolumn{2}{c}{ Força } & \multicolumn{2}{c}{ Resistência } \\
\cline { 2 - 11 } & Média & \multicolumn{1}{c}{$\sigma$} & Média & $\sigma$ & Média & $\sigma$ & Média & $\sigma$ & Média & $\sigma$ \\
\hline Controle $(\mathrm{n}=13)$ & 53,00 & 9,04 & 24,45 & 7,75 & 31,28 & 6,38 & 15,00 & 2,95 & 9,55 & 1,06 \\
Musculação $(\mathrm{n}=10)$ & 52,75 & 8,76 & 19,52 & 6,16 & 28,98 & 5,44 & 20,00 & 3,23 & 10,40 & 1,43 \\
Caminhada $(\mathrm{n}=11)$ & 57,00 & 9,56 & 24,28 & 5,47 & 29,92 & 4,18 & 17,00 & 4,02 & 9,20 & 0,93 \\
Hidroginástica $(\mathrm{n}=12)$ & 54,00 & 11,18 & 19,37 & 2,98 & 31,31 & 3,03 & 16,00 & 2,30 & 10,09 & 1,13 \\
Dança $(\mathrm{n}=10)$ & 53,00 & 9,02 & 19,21 & 4,41 & 33,73 & 4,27 & 15,00 & 4,34 & 10,31 & 0,99 \\
\hline
\end{tabular}

Em relação às variáveis do andar, a ANOVA indicou que os grupos são diferentes no comprimento do passo $\left(F_{4,51}=3,009 ; p<0,026\right)$ e no comprimento da passada $\left(F_{4,51}=2,85 ; p<0,033\right)$. $O$ teste post hoc de Tukey indicou que 0 grupo Controle é estatisticamente diferente do grupo Dança tanto no comprimento do passo ( $p<0,016$; Figura $2 a$ ) como no comprimento da passada $(p<0,022$; Figura $2 b)$. 


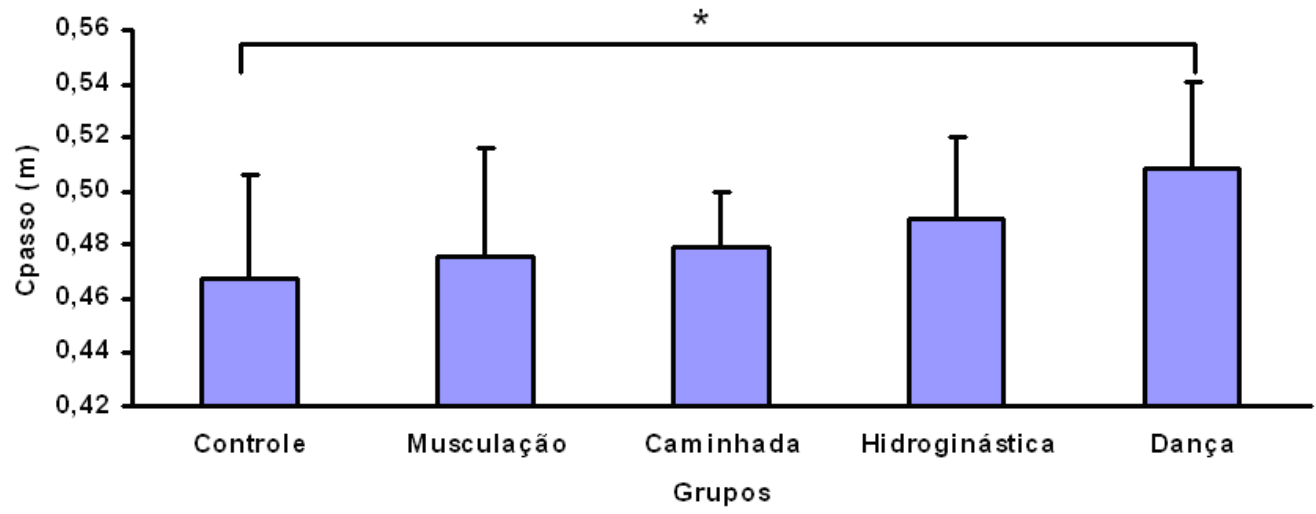

b

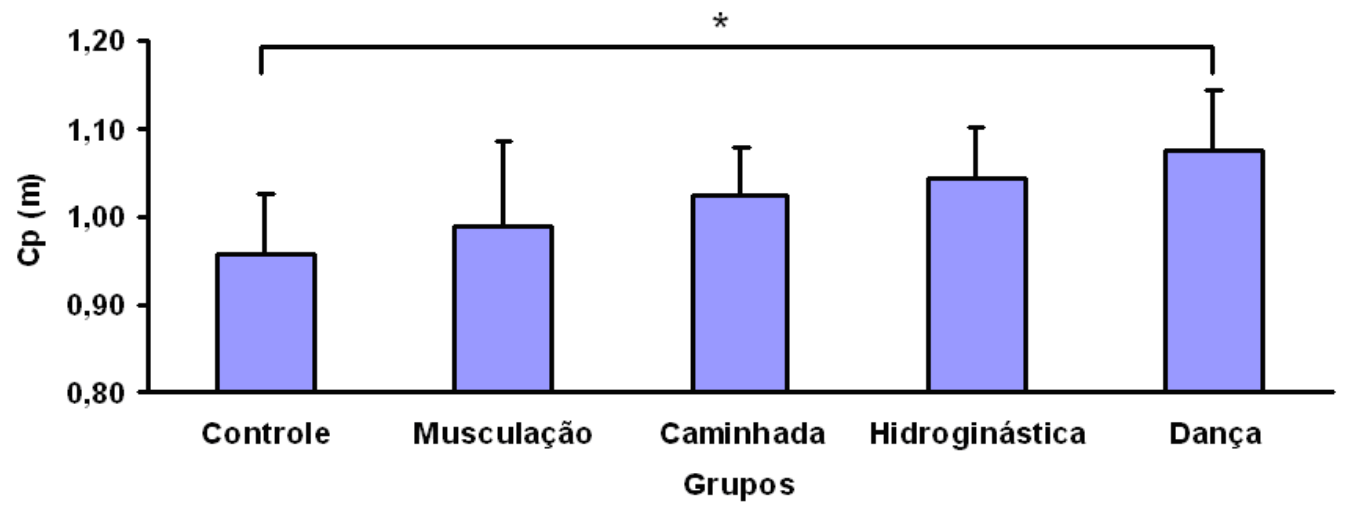

Figura 2. Médias e desvios-padrão do comprimento do passo (Cpass; a) e do comprimento da passada $(\mathrm{Cp} ; \mathrm{b}) . \mathrm{O}$ * representa a diferença estatisticamente significante entre o grupo Controle e o grupo Dança.

As demais variáveis dependentes do andar mostraram-se semelhantes entre os grupos (Tabela 3).

Tabela 3. Médias e desvios-padrão das variáveis do andar por grupo ( $\mathrm{Dp}=$ duração da passada; $\mathrm{Vp}=$ velocidade da passada; $\mathrm{Cad}=$ cadencia; $\mathrm{Dfbp}=$ duração da fase de balanço da passada; Dssp= duração do suporte simples da passada; $D d s p=$ duração do duplo suporte da passada).

\begin{tabular}{|c|c|c|c|c|c|c|c|c|c|c|}
\hline \multirow{2}{*}{ Variáveis } & \multicolumn{2}{|c|}{ Controle } & \multicolumn{2}{|c|}{ Musculação } & \multicolumn{2}{|c|}{ Caminhada } & \multicolumn{2}{|c|}{ Hidroginástica } & \multicolumn{2}{|c|}{ Dança } \\
\hline & Média & $\sigma$ & Média & $\sigma$ & Média & $\sigma$ & Média & $\sigma$ & Média & $\sigma$ \\
\hline & 1,00 & 0,09 & 0,99 & 0,06 & 1,03 & 0,07 & 3 & 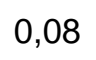 & 1,09 & 0,07 \\
\hline T &, 34 & ( & 1,00 & 0,16 & 0,99 & 0,11 & ו ו ו & , & 0,00 & 0,1 \\
\hline $2 \mathrm{~d}$ & 94 & 0,08 & 01 & 0,05 & 0,97 & 0,06 &, 97 & 0,08 & 0,92 & 0,11 \\
\hline & נט,ט & $1, r$ & (1) & 1,6 & 40,36 & 1,73 & 40,0 & 2,30 & (5) & 1,4 \\
\hline & 39,88 & 0,95 & 40,77 & 1,37 & 40,58 & 1,63 & 8 & 20 & 40 & 2,84 \\
\hline Ddsp (\%) &, 53 & 2,33 & 9,67 & 2,55 & 19,54 & 3,02 & 19,38 & 2,94 & 19,95 & 2,74 \\
\hline
\end{tabular}


Análises de Regressão Múltipla (stepwise) foram utilizadas para determinar as variáveis preditoras do comprimento do passo e do comprimento da passada. Todas as variáveis antropométricas, incluindo idade, de capacidade funcional, de nível de atividade física e do andar, exceto comprimento da passada para comprimento do passo e vice-versa, foram incluídas no modelo. Para o comprimento do passo, as variáveis velocidade da passada, duração da passada, coordenação e peso corporal foram identificadas como preditoras $\left(R^{2}=0,856 ; p<0,001\right)$ (Tabela 4). Para 0 comprimento da passada, as variáveis velocidade da passada, duração da passada e cadência foram identificadas como preditoras $\left(R^{2}=0,970 ; p<0,001\right)$ (Tabela 5).

Tabela 4. Variáveis preditoras do comprimento do passo, com os respectivos valores de Beta e significância.

\begin{tabular}{ccc}
\hline \hline Variáveis Preditoras & Beta & Sig \\
\hline $\operatorname{Vp}(\mathrm{m} / \mathrm{s})$ & 1,308 & 0,0001 \\
$\operatorname{Dp}(\mathrm{s})$ & 0,977 & 0,0001 \\
Coord $(\mathrm{s})$ & $-0,223$ & 0,0001 \\
Peso $(\mathrm{kg})$ & 0,158 & 0,005 \\
\hline
\end{tabular}

Tabela 5. Variáveis preditoras do comprimento da passada, com os respectivos valores de Beta e significância.

\begin{tabular}{ccc}
\hline \hline Variáveis Preditoras & Beta & Sig \\
\hline $\operatorname{Vp}(\mathrm{m} / \mathrm{s})$ & 1,541 & 0,0001 \\
$\mathrm{Dp}(\mathrm{s})$ & 0,789 & 0,0001 \\
$\mathrm{Cad}(\mathrm{pass} / \mathrm{s})$ & $-0,145$ & 0,032 \\
\hline
\end{tabular}

\subsection{Discussão}

A similaridade entre os grupos, observada na Tabela 1 quanto às variáveis idade, estatura, peso, IMC e percentual de gordura, revela a cuidadosa aplicação dos critérios de inclusão e exclusão. Esta similaridade também elimina a interferência destas características nos resultados obtidos.

O objetivo deste estudo foi comparar os efeitos de diferentes tipos de exercício nos parâmetros cinemáticos do andar de idosas, considerando as características antropométricas, a capacidade funcional e o nível de atividade 
física. Os resultados encontrados neste estudo para o nível de atividade física revelaram que o grupo controle foi diferente dos demais grupos que praticam exercício específico. Isto já era esperado visto que a literatura mostra que participar de programas de atividade física regular durante doze semanas melhora a aptidão funcional de mulheres idosas (NAKAMURA et al., 2006). Ainda, também indica que as participantes do grupo controle eram realmente inativas, atendendo ao critério de inclusão.

Vários estudos evidenciam os benefícios do exercício físico para um envelhecimento ativo e saudável, no entanto, políticas públicas voltadas a programas sistematizados envolvendo estas práticas ainda são incipientes, no sentido de sensibilizar e mobilizar a maior parte da população a participar de maneira regular desses programas. De acordo com uma pesquisa recente nas capitais brasileiras, a inatividade física atinge grande parte da população idosa, representando 50,3\% das mulheres e $65,4 \%$ dos homens acima dos 65 anos sem atividade (BRASIL, 2007). Giles-Corti e Donavan (2003) sinalizam outros fatores que estão associados ao sedentarismo, merecendo destaque as questões sócio-econômicas, gênero e contextos ambientais, como acesso a espaços para a prática de atividades físicas.

Em relação à capacidade funcional, apenas o componente força apresentou diferenças entre os grupos, indicando que o grupo controle difere do grupo Musculação. Programas de treinamento podem aumentar a força em indivíduos de todas as idades (TRANCOSO; FARINATTI, 2002) e o treinamento de força muscular em idosos promove melhora nas propriedades contráteis do músculo, bem como na força e na velocidade de contração (OCHALA et al., 2005). Entretanto, este resultado deve ser considerado com cautela, pois as atividades de dança, hidroginástica e caminhada desenvolvem força de membros inferiores e o teste de força aplicado no estudo envolveu membros superiores.

Quanto às variáveis do andar, o grupo controle foi estatisticamente diferente apenas do grupo Dança tanto no comprimento do passo, como no comprimento da passada. Este resultado não corrobora com os achados de outros estudos. Arantes et al. (2009), ao comparar praticantes de hidroginástica e de musculação, encontraram melhor desempenho nas variáveis espaciais e temporais do andar para as idosas que praticavam musculação. Ainda, Persch 
et al. (2009) observaram que a musculação foi eficiente em reverter os efeitos do envelhecimento nos parâmetros do andar e Lamoureux et al. (2002) verificaram que programas de fortalecimento muscular foram eficazes no sentido de ajudar os idosos a superar os desafios impostos pelo ambiente à locomoção. Vieira e Rabelo (2007) mostraram que a velocidade de caminhada foi maior para idosas participantes de hidroginástica e ginástica quando comparadas com as participantes de dança sênior.

Por outro lado, a dança, além de ser uma atividade física bem aceita pelos idosos, permite aquisição de novas habilidades e assessora na melhoria da capacidade motora, permitindo a realização de movimentos mais complexos (CARLI, 2000; SILVA; MAZO, 2007), em particular referente à coordenação motora tanto para os membros superiores quanto para os inferiores (SEBASTIÃO et al., 2008). Ainda, a dança influencia positivamente o equilíbrio corporal e a força muscular (COELHO et al., 2008), além de prevenir o declínio cognitivo (BOCALINI et al., 2007) e diminui o risco de quedas (SEBASTIÃO et al., 2008; SHIGEMATSU et al., 2002).

A dança, em algumas situações e determinadas regiões, constitui em uma importante manifestação cultural, realçada em sua gestualidade e festividades (BOCALINI et al., 2007). Os resultados positivos do padrão do andar encontrados no grupo dança podem ser explicados pelas características dos ritmos praticados, majoritariamente Forró e Xaxado. Estes ritmos envolvem movimentos cadenciados em várias direções, com giros, deslocamentos e mudanças na base suporte. Ainda, o Forró e o Xaxado podem ser caracterizados como ritmos rápidos e, como requerem que os deslocamentos acompanhem o ritmo imposto, os pés se movimentam com pequenas amplitudes de movimento do tornozelo. Esta exigência pode ter incrementado os níveis de força dos músculos quadríceps para elevar o membro inferior do solo e propiciado aumento tanto no comprimento do passo como da passada em relação ao grupo controle.

$\mathrm{Na}$ análise para determinar as variáveis preditoras do comprimento do passo e do comprimento da passada, todas as variáveis antropométricas, idade, capacidade funcional, nível de atividade física e parâmetros do andar, exceto comprimento da passada para comprimento do passo e vice-versa, foram incluídas no modelo. Para o comprimento do passo, as variáveis 
velocidade da passada, duração da passada, coordenação e peso corporal foram identificadas. Para o comprimento da passada, as variáveis velocidade da passada, duração da passada e cadência foram identificadas como preditoras. A combinação destas variáveis revela o intrincado relacionamento entre os parâmetros espaciais e temporais do andar.

Para o comprimento do passo, a presença das variáveis coordenação e peso corporal como preditoras indica que além dos parâmetros do andar, componentes da capacidade funcional e características antropométricas também interagem para predizer a variabilidade do comprimento do passo. $O$ comprimento do passo é considerado um preditor da velocidade de andar, pois determina o espaço percorrido durante a fase de balanço (ROSE; GAMBLE, 2006; PERRY, 1992). Aumentos no comprimento da passada também podem explicar aumentos na velocidade de andar, visto que maiores distâncias podem ser alcançadas em um menor espaço de tempo (PRINCE et al., 1997).

O presente estudo apresenta algumas limitações. A não inclusão de participantes do gênero masculino deveu-se ao fato de que poucos homens idosos realizam atividades como hidroginástica e dança. Entretanto, a principal limitação deste estudo está relacionada ao controle da intensidade, frequência e duração das sessões, bem como da progressão da intensidade do esforço. Apesar desta limitação, este estudo foi capaz de revelar poucas diferenças quanto ao nível de atividade física, parâmetros estruturais e funcionais e nas variáveis espaciais do andar entre os tipos de exercícios. A limitação quanto aos parâmetros do exercício somente pode ser eliminada em estudos de intervenção, que é a proposta do Estudo 2 desta tese.

\subsection{Conclusões}

Os resultados do presente estudo permitem concluir que: a) a capacidade funcional dos idosos ativos e sedentários apresentou poucas diferenças entre os tipos de exercício, onde apenas o componente força do grupo Musculação foi diferente ao grupo Controle; b) o padrão espacial do andar (comprimento do passo e da passada) apenas do grupo Dança foi diferente do grupo Controle; e c) houve um forte relacionamento entre os parâmetros espaciais e temporais do andar revelado pelas variáveis preditoras do comprimento do passo e da passada. 


\section{ESTUDO 2: Mudanças no padrão de andar, nas características antropométricas e na capacidade funcional de idosas após participação em programa de exercícios generalizados.}

\subsection{Introdução}

As mudanças que acontecem na locomoção de idosos são amplamente descritas e o interesse em se estudar idosos está pautado no fato de que a expectativa de vida vem aumentando nos últimos anos. Estudar o padrão de andar de idosos tem se mostrado bastante relevante, visto que suas mudanças podem estar relacionadas com as causas de quedas observadas nessa população (WINTER, 1991). O processo de envelhecimento está associado a modificações desfavoráveis na forma de andar, no aumento do tempo necessário para se percorrer certa distância e na necessidade de se utilizar apoio adicional para o deslocamento (MENZ et al., 2003; SHKURATOVA et al., 2004).

As razões para as modificações no padrão de andar dos idosos têm sido atribuídas a alguns fenômenos inerentes ao envelhecimento, como alterações na capacidade de controle do equilíbrio (WINTER, 1995), na oscilação corporal na postura ereta (PRIOLI et al., 2006; PRIOLI et al., 2005), na força muscular (WINTER et al., 1990), na quantidade de atividade física (GOBBI; ANSARAH, 1992), na elasticidade muscular e na mobilidade articular nos membros inferiores (PRINCE et al., 1997; SPIRDUSO, 1995) e no tempo para processamento e resposta a estímulos ambientais (SHUMWAY-COOK; WOOLLACOTT, 1995). 
Ainda, poucas diferenças foram observadas quando 0 andar foi mensurado em esteira rolante (VAN EMMERIK et al., 2005), talvez porque a velocidade da esteira é dirigida e, portanto, não corresponde ao andar natural. Da mesma forma, estudos têm envolvido idosos saudáveis de ambos os gêneros (SILVEIRA et al., 2006) ou apenas homens (FLORINDO et al., 2004) e pouco é conhecido em relação às mudanças específicas em mulheres idosas. As atividades domésticas, especialmente as que envolvem o andar, como varrer, continuam normalmente sendo realizadas pelas mulheres independente da idade. A realização dessas atividades aliada à maior aderência em programas de exercícios físicos pode favorecer a manutenção dos parâmetros do andar observados em adultos jovens. Por outro lado, Lebrão e Laurenti (2005) encontraram, em seu estudo, que $26,5 \%$ dos idosos apresentavam dificuldade de realizar as tarefas da vida diária, sendo que as atividades que eles mais apresentaram dificuldades de realização eram agachar-se, levantarse da cadeira e subir um andar de escadas.

As limitações físicas e psicológicas, próprias da velhice, devem ser analisadas antes do início de um programa de exercícios. O desejável é que o início seja lento e gradual, respeitando sempre os limites de cada indivíduo. A avaliação inicial é imprescindível, uma vez que muitos idosos têm doenças e tomam medicamentos. Hipertensão, diabetes, osteoporose, doença cardiovascular e problemas articulares são algumas das mais comuns entre esta população (MATSUDO et al., 2000).

Apesar das fortes evidências dos benefícios de programas de exercícios aeróbios e resistidos para a população idosa (CHODZKO-ZAJKO et al., 2009), novos programas de exercícios estão sendo pensados no sentido de atender aos interesses e necessidades desta população de forma global e, assim, trabalhar todos os componentes da aptidão física. O exercício generalizado tem como objetivo principal o desenvolvimento das valências físicas mais requisitadas na vida diária (MIYASIKE-DA-SILVA et al., 2002). Um programa de exercícios generalizados se caracteriza principalmente por exercícios que desenvolvam todos os componentes da aptidão física, com reflexo sobre a qualidade de vida (CARVALHO et al., 2004).

Neste contexto, o objetivo deste estudo foi avaliar os parâmetros do andar de idosas sedentárias antes e após o envolvimento em um programa de 
exercícios generalizados, considerando também as características antropométricas, a capacidade funcional e o nível de atividade física, conforme o Estudo 1.

No Estudo 1 foi possível observar que programas específicos como hidroginástica, musculação e caminhada não evidenciaram mudanças no padrão de andar quando comparados com grupo controle, devido às suas características de transversalidade. O estudo de intervenção foi desenhado para suprir as limitações apresentadas no Estudo 1, tendo em vista que o controle dos parâmetros do programa de exercícios em termos de intensidade, frequência e duração das sessões, bem como da progressão da intensidade do esforço, somente é possível em um estudo experimental.

\subsection{Material e Método}

Foi realizada uma pesquisa do tipo estudo clínico antes e depois.

\section{Participantes}

Foram recrutadas intencionalmente em grupos de terceira idade, 32 mulheres sedentárias, 60 anos ou mais, para participar do projeto de extensão "Viva a Velhice com Plenitude", do Departamento de Educação Física da Universidade Estadual da Paraíba-PB, sendo que 17 delas atenderam aos critérios de inclusão do estudo: gênero feminino, idade acima de 60 anos, enquadrar-se no $1^{\circ}$ tercil do nível de atividade física, não envolvimento em atividade física regular por pelo menos 02 meses. Os critérios de exclusão foram: história ou caso de infarto do miocárdio, angina pectoris e/ou insuficiência cardíaca; diabetes mellitus do tipo 1, insulina-dependente; problemas ósteo-mio-articulares que dificultem a locomoção e uso regular de medicamentos que interferem no equilíbrio. Nenhuma das participantes do Estudo 1 foi incluída no presente estudo.

\section{Procedimentos}

Após a assinatura do termo de consentimento livre e esclarecido (Anexo 1b), uma anamnese foi empregada para utilização dos critérios de inclusão e exclusão. Os procedimentos para avaliar o padrão de andar das idosas, as características antropométricas, a capacidade funcional e o nível de atividade física foram iguais aos utilizados no Estudo 1. 
O programa de exercícios generalizados (PEG) foi desenvolvido em um período de 4 meses, incluindo atividades de aquecimento, alongamento, dança, musculação e atividades recreativas. Na elaboração do programa, os componentes da capacidade funcional (resistência aeróbia, força muscular, coordenação motora, flexibilidade e equilíbrio corporal) foram considerados. $\mathrm{O}$ PEG constou de 48 sessões, sendo que mais 13 sessões iniciais de adaptação das idosas e da equipe de aplicadores foram realizadas. A ênfase das sessões de adaptação foi na reeducação do movimento das idosas. As sessões tiveram frequência de 3 vezes por semana e duração de 60 minutos, constando cada uma delas de três partes: a) Parte inicial: aquecimento e alongamento (10'); b) Parte principal: atividade da sequência que era enfocada (40'); c) Parte final: alongamento e relaxamento (10'), sendo que os componentes da resistência aeróbia e flexibilidade foram trabalhados concomitantemente com os outros componentes (FIGURA 3). Ainda, música em diferentes ritmos esteve presente em todas as partes de todas as sessões.

\begin{tabular}{|c|c|c|}
\hline $\begin{array}{c}\text { Coordenação }+ \\
\text { Resistência aeróbia }+ \\
\text { Flexibilidade }\end{array}$ & $\begin{array}{c}\text { Força muscular }+ \\
\text { Resistência aeróbia }+ \\
\text { Flexibilidade }\end{array}$ & $\begin{array}{c}\text { Equilíbrio corporal }+ \\
\text { Resistência aeróbia }+ \\
\text { Flexibilidade }\end{array}$ \\
\cline { 2 - 3 } & &
\end{tabular}

Figura 3. Representação das sequências empregadas para distribuição dos componentes da capacidade funcional entre as sessões.

O PEG foi pensado e discutido pelos coordenadores da pesquisa juntamente com os estagiários, em reuniões de planejamento. Precedendo 0 período de adaptação, ocorreu o treinamento dos estagiários aplicadores do programa, que consistiu basicamente na aplicação simulada das atividades a serem desenvolvidas junto às idosas. A regência das aulas foi distribuída entre os estagiários, sendo que o coordenador esteve presente em todas as aulas. $\mathrm{O}$ programa foi distribuído em 4 fases, compostas de 12 sessões cada uma delas, onde foi empregado o princípio da sobrecarga e adaptação e a intensidade do treino foi gradualmente aumentada (aumento progressivo de carga ou número de repetições), como pode ser visto no Quadro 1. Foram utilizados dois frequencímetros, de forma randomizada nas idosas, para assegurar que a frequência cardíaca se mantivesse entre 60 a $85 \%$ da frequência cardíaca máxima, como preconiza o American College of Sports Medicine (ACSM, 2006). 


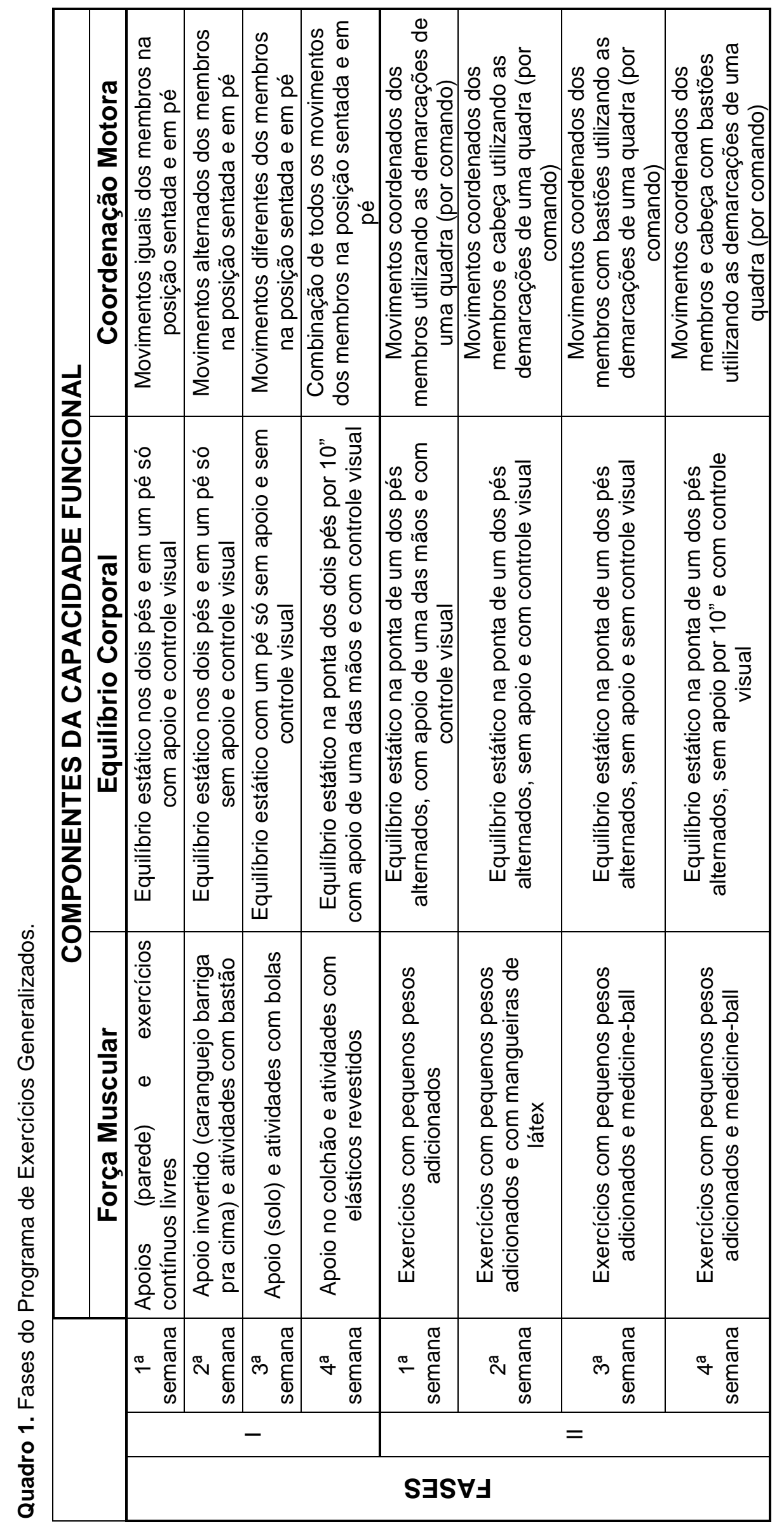




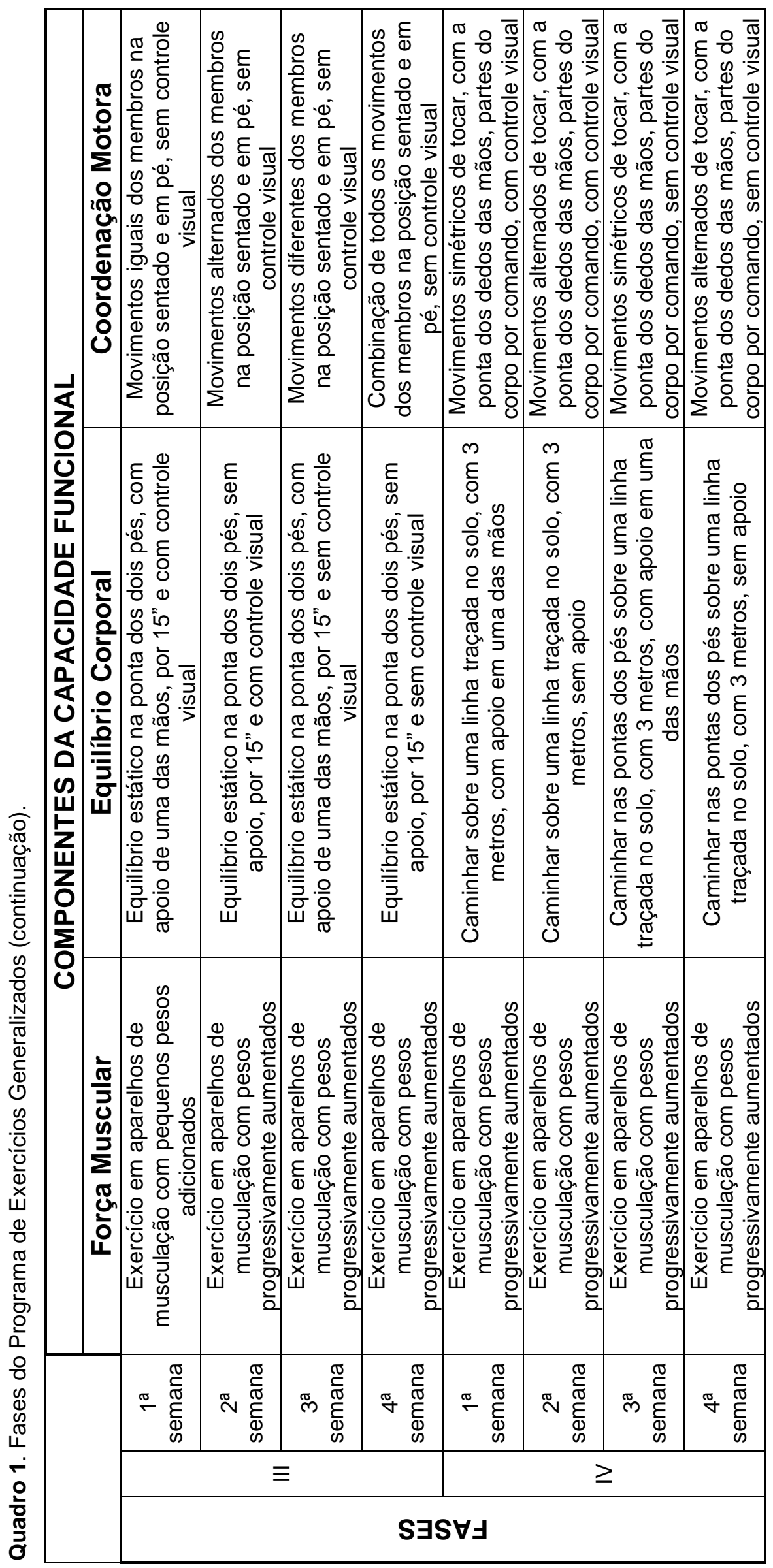


As participantes do estudo foram avaliadas duas vezes em um período de quatro meses. A primeira avaliação de pré-treinamento foi realizada antes do início das atividades do programa e a segunda avaliação, de póstreinamento, foi realizada na sessão seguinte após o período final das atividades do programa.

\section{Análise Estatística}

As variáveis dependentes não atingiram os critérios de normalidade (Shapiro-Wilk) e homogeneidade das variâncias (Levene) e, portanto, foram tratadas estatisticamente por meio do teste não-paramétrico de Wilcoxon. Ainda, foram utilizadas análises de Regressão Múltipla (stepwise) para determinar as variáveis preditoras das variáveis dependentes da marcha que apresentaram mudanças significativas com a intervenção. Todas as variáveis antropométricas, incluindo idade, de capacidade funcional, de nível de atividade física e do andar foram incluídas no modelo. O nível de significância pré-estabelecido para todas as análises foi $p<0,05$.

\subsection{Resultados}

A Tabela 6 apresenta a caracterização das participantes nos momentos pré e pós intervenção.

Tabela 6. Caracterização dos participantes ( $n=$ número de participantes, estatura, peso, IMC= índice de massa corporal, idade, DCT= dobra cutânea triciptal, $\sigma=$ desvio-padrão), nos momentos pré e pós-intervenção.

\begin{tabular}{ccccc}
\hline \multirow{2}{*}{ Componentes } & Pré & Pós & $Z$ & $P<0,05$ \\
\hline Amostra $(\mathrm{n})$ & 17 & 16 & & \\
Estatura (m) & $1,49 \pm 0,05$ & $1,49 \pm 0,05$ & 0,00 & 1,000 \\
Peso (kg) & $65,17 \pm 10,05$ & $64,60 \pm 9,54$ & $-0,31$ & 0,733 \\
IMC (peso/altura $\left.{ }^{2}\right)$ & $30,01 \pm 3,90$ & $30,01 \pm 3,90$ & 0,40 & 0,691 \\
Idade (anos) & $67,69 \pm 4,80$ & $67,94 \pm 4,80$ & $-2,00$ & 0,046 \\
DCT (mm) & $29,06 \pm 4,62$ & $27,05 \pm 3,63$ & $-3,17$ & 0,002 \\
\hline
\end{tabular}


Quanto ao nível de atividade física, mensurado pelo questionário de Baecke tanto no componente de atividade física como no escore total, os resultados encontrados mostram que houve aumento no nível de atividade física do grupo após o envolvimento no PEG, conforme o esperado (FIGURA 4).

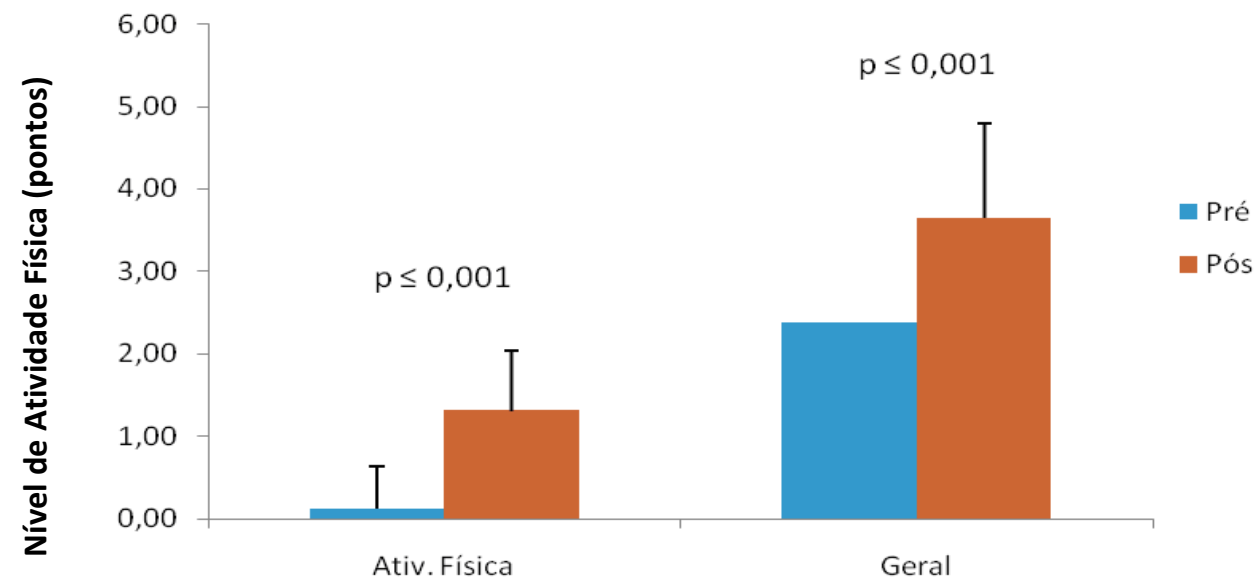

Figura 4. Médias e desvios-padrão do nível de atividade física antes e após o treinamento nos componentes atividade física e escore geral no questionário de Baecke.

Os níveis de capacidade funcional, separados por componente são apresentados na Tabela 7. O teste de Wilcoxon revelou que todos os componentes apresentaram significância quando comparados os escores antes e após a intervenção.

Tabela 7. Médias e desvios-padrão $(\sigma)$ dos componentes da capacidade funcional pré e pósintervenção, valor do teste de Wilcoxon (Z) e significância.

\begin{tabular}{lcccc}
\hline \multirow{2}{*}{ Componentes } & \multicolumn{2}{c}{ Média $\pm \sigma$} & & \\
& Pré & Pós & Z & $\mathbf{P}<\mathbf{0 , 0 5}$ \\
\hline Flexibilidade $(\mathrm{cm})$ & $50,34 \pm 7,80$ & $55,89 \pm 6,98$ & $-2,59$ & 0,010 \\
Coordenação $(\mathrm{s})$ & $21,18 \pm 6,89$ & $13,45 \pm 4,93$ & $-3,46$ & 0,001 \\
Agilidade (s) & $28,97 \pm 3,07$ & $26,48 \pm 3,00$ & $-2,69$ & 0,007 \\
Força (n- rep.) & $16,00 \pm 2,50$ & $22,13 \pm 3,67$ & $-3,31$ & 0,001 \\
Capacidade Aeróbia (min) & $10,14 \pm 1,05$ & $9,55 \pm 0,93$ & $-2,78$ & 0,005 \\
\hline
\end{tabular}

O teste de Wilcoxon evidenciou efeito do PEG nas variáveis do andar (TABELA 8) que estão mais relacionados aos parâmetros temporais [duração da passada (Dp), velocidade da passada $(V p)$, cadência (Cad) e duração das fases de suporte simples (Dssp) e duplo suporte (Ddsp)]. As variáveis 
relacionadas aos parâmetros espaciais (comprimento do passo e da passada) não foram afetadas pelo PEG ( $p>0,05)$.

Tabela 8. Médias, desvios-padrão $(\sigma)$, valor do teste de Wilcoxon $(Z)$ e significância das variáveis da marcha pré e pós-intervenção.

\begin{tabular}{lcccc}
\hline \multicolumn{1}{c}{ Componentes } & \multicolumn{2}{c}{ Média $\pm \sigma$} & & \\
& Pré & Pós & $\mathbf{Z}$ & $\mathbf{P}<\mathbf{0 , 0 5}$ \\
\hline Comprimento do passo $(\mathrm{m})$ & $0,48 \pm 0,04$ & $0,50 \pm 0,04$ & $-0,62$ & 0,535 \\
Comprimento da passada $(\mathrm{m})$ & $1,005 \pm 0,06$ & $1,046 \pm 0,08$ & $-0,98$ & 0,326 \\
Duração da passada $(\mathrm{s})$ & $1,07 \pm 0,09$ & $1,00 \pm 0,06$ & $-2,72$ & 0,007 \\
Velocidade da passada $(\mathrm{m} / \mathrm{s})$ & $0,95 \pm 0,10$ & $1,05 \pm 0,09$ & $-2,53$ & 0,011 \\
Cadência (pass/s) & $0,94 \pm 0,07$ & $1,00 \pm 0,06$ & $-2,74$ & 0,006 \\
Duração suporte simples $(\%)$ & $39,59 \pm 1,25$ & $40,66 \pm 1,07$ & $-2,75$ & 0,023 \\
Duração duplo suporte $(\%)$ & $20,40 \pm 2,44$ & $18,61 \pm 1,87$ & $-2,33$ & 0,020 \\
\hline
\end{tabular}

Foram utilizadas análises de Regressão Múltipla (stepwise) para determinar as variáveis preditoras da duração da passada (s), velocidade da passada $(\mathrm{m} / \mathrm{s})$, cadência (pass/s) e duração das fases de suporte simples e duplo suporte na passada (\%). A Tabela 9 , referente à duração da passada, mostra as variáveis preditoras pré $\left(R^{2}=0,994 ; p<0,001\right)$ e pós-intervenção $\left(R^{2}=0,995 ; p<0,001\right)$, sendo que a melhor preditora nos dois momentos foi a variável cadência.

Tabela 9. Variáveis preditoras da duração da passada pré e pós-intervenção, com os respectivos valores de Beta e significância.

\begin{tabular}{cccc}
\hline \hline & Variáveis Preditoras & Beta & $\mathbf{P}$ \\
\hline \multirow{2}{*}{ Pré } & Cadência (pass/s) & $-0,996$ & 0,001 \\
& Comprimento do passo (cm) & $-0,052$ & 0,029 \\
\hline \multirow{2}{*}{ Pós } & Cadência (pass/s) & $-0,890$ & 0,001 \\
& Coordenação (s) & 0,161 & 0,001 \\
\hline
\end{tabular}

A Tabela 10 mostra as variáveis preditoras da velocidade da passada antes $\left(R^{2}=0,999 ; p<0,001\right)$ e após a intervenção $\left(R^{2}=1,000 ; p<0,001\right)$. Para as duas análises, as variáveis que melhor explicam o modelo são o comprimento da passada e a cadência na pré-intervenção e o comprimento e a duração da passada na pós-intervenção. 
Tabela 10. Variáveis preditoras da velocidade da passada pré e pós-intervenção, com os respectivos valores de Beta e significância.

\begin{tabular}{cccc}
\hline & Variáveis Preditoras & Beta & P \\
\hline \multirow{4}{*}{ Pré } & Comprimento da passada $(\mathrm{cm})$ & 0,593 & 0,001 \\
& Cadência (pass/s) & 0,696 & 0,001 \\
& Duração da fase de balanço (\%) & 0,069 & 0,001 \\
& Idade (anos) & 0,031 & 0,001 \\
\hline \multirow{3}{*}{ Pós $\quad$ Comprimento da passada (cm) } & 0,898 & 0,001 \\
& Duração da passada (s) & $-0,697$ & 0,001 \\
& IMC (categoria) & $-0,038$ & 0,001 \\
& Dobra Cutânea Triciptal (mm) & 0,021 & 0,007 \\
& Idade (anos) & 0,016 & 0,032 \\
\hline
\end{tabular}

A Tabela 11 mostra as variáveis preditoras da cadência pré-intervenção $\left(R^{2}=0,994 ; p<0,001\right)$ e pós-intervenção $\left(R^{2}=0,994 ; p<0,001\right)$, sendo que a melhor preditora nos dois momentos foi a variável duração da passada.

Tabela 11. Variáveis preditoras da Cadência pré e pós-intervenção, com os respectivos valores de Beta e significância.

\begin{tabular}{cccc}
\hline \hline & Variáveis Preditoras & Beta & P \\
\hline \multirow{2}{*}{ Pré } & Duração da passada $(\mathrm{s})$ & $-0,995$ & 0,001 \\
& Comprimento do passo $(\mathrm{cm})$ & $-0,052$ & 0,028 \\
\hline \multirow{2}{*}{ Pós } & Duração da passada $(\mathrm{s})$ & $-1,113$ & 0,001 \\
& Cooordenação $(\mathrm{s})$ & 0,174 & 0,001 \\
\hline
\end{tabular}

A Tabela 12 apresenta as variáveis preditoras da duração do suporte simples antes $\left(R^{2}=0,999 ; p<0,001\right)$ e após a intervenção $\left(R^{2}=0,996 ; p<0,001\right)$. As variáveis que melhor responderam ao modelo, tanto na pré quanto na pósintervenção, foram duração do duplo suporte e duração da fase de balanço. Entretanto, cabe destacar que houve uma combinação de variáveis do andar com variáveis antropométricas, de capacidade funcional e de nível de atividade física na predição da variabilidade da duração do suporte simples e, ainda, que esta combinação se alterou como efeito do PEG. 
Tabela 12. Variáveis preditoras da duração do suporte simples pré e pós-intervenção, com os respectivos valores de Beta e significância.

\begin{tabular}{cccc}
\hline \hline & Variáveis Preditoras & Beta & P \\
\hline \multirow{4}{*}{ Pré } & Duração do duplo suporte (\%) & $-1,944$ & 0,001 \\
& Duração da fase de balanço (\%) & $-1,357$ & 0,001 \\
& Dobra Cutânea Triciptal (mm) & $-0,058$ & 0,001 \\
& Força (rep) & $-0,038$ & 0,006 \\
Estatura (m) & 0,028 & 0,035 \\
\hline \multirow{3}{*}{ Pós } & Duração do duplo suporte (\%) & $-1,751$ & 0,001 \\
& Duração da fase de balanço (\%) & $-1,271$ & 0,001 \\
& Atividade de Lazer (pts) & $-0,116$ & 0,002 \\
& IMC (peso/altura $\left.{ }^{2}\right)$ & 0,066 & 0,021 \\
& Comprimento do passo (cm) & 0,070 & 0,027 \\
\hline
\end{tabular}

A Tabela 13 mostra as variáveis preditoras da duração do duplo suporte pré $\left(R^{2}=1,000 ; p<0,001\right)$ e pós-intervenção $\left(R^{2}=0,999 ; p<0,001\right)$. Nas duas análises, as variáveis que melhor responderam ao modelo nos dois momentos foram a duração da fase de balanço e a duração do suporte simples. Semelhante ao observado para a duração do suporte simples, a duração do duplo suporte também foi predita pela combinação de variáveis do andar, antropométricas, de capacidade funcional e de nível de atividade física.

Tabela 13. Variáveis preditoras da duração do duplo suporte pré e pós-intervenção, com os respectivos valores de Beta e significância.

\begin{tabular}{cccc}
\hline \hline & Variáveis Preditoras & Beta & P \\
\hline \multirow{4}{*}{ Pré } & Duração da fase de balanço (\%) & $-0,699$ & 0,001 \\
& Duração do suporte simples (\%) & $-0,514$ & 0,001 \\
& Dobra Cutânea Triciptal (mm) & $-0,030$ & 0,001 \\
Força (rep) & $-0,019$ & 0,007 \\
Estatura (m) & 0,015 & 0,030 \\
\hline \multirow{3}{*}{ Pós } & Duração da fase de balanço (\%) & $-0,725$ & 0,001 \\
& Duração do suporte simples (\%) & $-0,568$ & 0,001 \\
& Atividade de Lazer (pts) & $-0,067$ & 0,002 \\
& IMC (peso/altura $\left.{ }^{2}\right)$ & 0,038 & 0,020 \\
& Comprimento do passo $(\mathrm{cm})$ & 0,038 & 0,034 \\
\hline
\end{tabular}




\subsection{Discussão}

O objetivo deste estudo foi avaliar os parâmetros do andar de idosas sedentárias antes e após o desenvolvimento de um programa de exercícios generalizados, considerando também as características antropométricas, a capacidade funcional e o nível de atividade física, conforme o Estudo 1. De acordo com o esperado, O PEG influenciou positivamente todos os componentes da capacidade funcional, reduziu os valores de dobra cutânea triciptal e afetou principalmente os parâmetros temporais do andar.

Em relação às variáveis antropométricas, apesar do PEG não ter provocado mudanças no IMC, houve diminuição de cerca de $7,5 \%$ na dobra cutânea tricipital. $O$ fato do IMC não ter sofrido alteração parece se justificar pela inversão de densidade corporal, pelo aumento da massa muscular e pela diminuição de massa gorda após a intervenção de 4 meses. Em um estudo populacional com idosos residentes em São Paulo, Barbosa et al. (2005) encontraram um valor médio de DCT de $25,2 \mathrm{~mm}$ em mulheres; Menezes e Marucci (2005) encontraram um valor médio de $21,7 \mathrm{~mm}$ em idosos institucionalizados de Fortaleza; e Mastroeni (2004), em Joinville, encontrou valores médios de $21,9 \mathrm{~mm}$ em idosos. Os valores para a DCT encontrados neste estudo $(27,05 \mathrm{~mm})$, mesmo após o PEG, são maiores do que os encontrados em outros estudos; todavia se aproxima bastante com os achados de Queiroz e Murano (2008), na Bahia, onde o valor médio da DCT foi de 26,6 mm. Apesar do PEG ter sido positivo quanto à perda de gordura, os altos valores encontrados requerem atenção, pois a obesidade é fator agravante para outras doenças que modificam as condições de saúde do idoso. Desta forma, os resultados deste estudo mostram a necessidade de um desenho de intervenção compartilhada com outras áreas de conhecimento, visto a complexidade da temática em questão.

Os resultados encontrados para o nível de atividade física reforçam a importância do idoso se manter ativo (GOBBI et al., 2007), pois além de melhorar as capacidades físicas e mentais, o exercício repercute também na esfera social, mantendo e melhorando a independência e a autonomia do idoso (ZAITUNE et al., 2007). De acordo com a WHO (2004), a inatividade física associada ao sobrepeso e à obesidade colabora de forma significante para o 
aumento de doenças crônicas e incapacidades, afetando assim a qualidade de vida dos idosos.

A capacidade funcional deve ser vista como um novo componente no modelo de saúde de idosos (RAMOS, 2003). Estudos recentes no Brasil apresentam evidências de que programas de exercícios trazem melhorias nos componentes da capacidade funcional (SEBASTIÃO et al.,2008; SILVA et al., 2010; CIPRIANI et al., 2010). Os resultados do presente estudo revelaram que houve melhora significativa em todos os componentes da capacidade funcional avaliados após quatro meses de aplicação do PEG. Estes achados reforçam a importância de se pensar programas de exercícios que contemplem todos os componentes da capacidade funcional, visto que eles são imprescindíveis à realização de tarefas da vida diária. Assim, a melhoria da capacidade funcional vem sendo apontada como uma estratégia de prevenção dentro de uma nova política voltada para a qualidade de vida do idoso (VERAS, 2009).

O PEG promoveu um ganho expressivo na flexibilidade de idosas inativas. A flexibilidade foi trabalhada no PEG por meio de alongamentos com método estático de forma ativa. É importante ainda ressaltar que na montagem do programa, o componente da flexibilidade estava presente em todas as sessões, trabalhado na primeira e última parte da aula. Os exercícios de alongamento eram aplicados objetivando a melhora na amplitude de movimento articular. Outros estudos que empregaram um protocolo de treinamento com um período da aula determinado para o trabalho de flexibilidade também obtiveram resultados positivos (ETCHEPARE et al., 2003; VALE et al., 2004), porém o mesmo não aconteceu nos estudos de Rebelatto et al. (2006) e Ribeiro et al. (2009). Rebelatto et al. (2006), em um programa de 58 semanas, justificaram os resultados pouco expressivos neste componente da capacidade funcional por questões relacionadas à programação e à intensidade dos exercícios. Ribeiro et al. (2009), ao trabalharem a flexibilidade em um programa generalizado, atribuíram a ausência de efeitos à característica generalista do programa. Assim, os resultados obtidos pelo PEG, ao trabalhar especificamente a flexibilidade em dois momentos de cada sessão, avançam o conhecimento sobre os efeitos de programas específicos e generalizados sobre a flexibilidade. 
As atividades do cotidiano geralmente necessitam da combinação de movimentos (SPIRDUSO, 2005) e, desta forma, a manutenção da coordenação motora pode resultar em maior independência, bem como auxiliar positivamente os demais componentes da capacidade funcional (SEBASTIÃO et al., 2008). Em relação à coordenação, este estudo revelou que o PEG foi efetivo em melhorar a coordenação motora. Uma possível explicação pode estar relacionada com a diversidade de exercícios empregados. Estes achados corroboram com os encontrados por Polastri et al. (1999) e Dias e Duarte (2005), que observaram melhoras expressivas na coordenação motora de membros superiores após a aplicação de um programa de ginástica generalizada. Ribeiro et al. (2009) também observaram influência positiva de um programa de ginástica generalizada de 24 semanas sobre a coordenação motora de idosas.

O PEG também promoveu melhoras significantes na agilidade e no equilíbrio dinâmico. Idosos ativos, engajados em programas de exercício, melhoram seus desempenhos nestes componentes da capacidade funcional. Teixeira et al. (2007) verificaram que idosos ativos apresentam níveis mais altos de agilidade quando comparados a idosos sedentários. Ferreira e Gobbi (2003) afirmam que idosas que praticam atividades físicas supervisionadas regularmente apresentam melhores níveis de agilidade geral que as mulheres não treinadas. Miyasike-da-Silva et al. (2002) avaliaram a agilidade e o equilíbrio dinâmico de 26 indivíduos fisicamente ativos que participaram de um programa de atividade física generalizada sem uma programação específica para tais componentes (caminhadas, jogos recreativos, ginástica, massagens, entre outros) e observaram melhoras expressivas em relação aos valores iniciais de agilidade e equilíbrio dinâmico. Além disso, os efeitos do programa aplicado por Miyasike-da-Silva et al. (2002) foram mantidos após o término. É importante ressaltar que o PEG foi planejado de forma que a parte principal das aulas foi designada aos componentes de coordenação motora, de equilíbrio corporal e de força, tendo a flexibilidade e a capacidade aeróbia trabalhadas concomitantemente com as demais.

A força muscular é considerada um dos componentes mais importantes dentro de um programa de treinamento, sendo indiscutíveis seus benefícios para pessoas idosas. Todavia, ainda não há consenso sobre a combinação dos 
parâmetros do treinamento (frequência, intensidade e duração) mais apropriada para se obter a melhor dose-resposta em pessoas idosas (SILVA; FARINATTI, 2007; MISIC et al., 2009). A força muscular de idosos pode ser melhorada por meio de um programa de treinamento com sobrecargas, pois um treinamento de força pode melhorar a função e as estruturas musculares, articulares e ósseas em qualquer idade (HUNTER et al., 2004; FRONTERA et al., 2003; VALKEINEN et al., 2004; SILVA; FARINATTI, 2007). Os achados do presente estudo corroboram com esses trabalhos citados e mostram que 0 treinamento específico de força em apenas uma sessão semanal dentro um programa de exercícios generalizados foi suficiente para promover incrementos na força muscular. Por outro lado, Carvalho-Alves e Medeiros (2004), ao combinar um programa de atividade física generalizada com exercícios resistidos em homens e mulheres idosos verificaram melhoras no controle postural e ajuste facilitado das cargas apropriadas aos grupos musculares. Combinado com os resultados do Estudo 1, é possível afirmar que não apenas o envolvimento em Musculação como no PEG promovem melhoras significativas na força muscular.

O PEG também foi eficiente em promover melhoras significativas para a resistência aeróbia, mesmo com este componente não sendo trabalhado de forma específica. Estes resultados reafirmam a necessidade de se manter uma vida fisicamente ativa, independente da idade. Os exercícios aeróbios desenvolvem a reserva funcional cardiovascular e atenuam suas disfunções (MOSTARDA et al., 2009). A melhoria da resistência aeróbia é determinada pela intensidade, frequência e duração do exercício e do nível inicial de aptidão física. Lanuez e Jacob Filho (2008) observaram que o exercício aeróbio, caracterizado pela caminhada, proporcionou além do incremento já esperado na resistência aeróbia, também melhoras nos parâmetros do equilíbrio. Ainda, Sebastião et al. (2008) observaram que um programa de dança de quatro meses foi suficiente para manutenção da resistência aeróbia geral em idosos que possuíam um bom nível inicial deste componente.

O exercício generalizado tem o propósito de atender às necessidades cotidianas do idoso, visto que este formato possibilita o treinamento de várias habilidades e capacidades físicas (MIYASIKE-DA-SILVA et al., 2002). Assim, este estudo mostra que a aplicação do PEG com as características propostas 
foi determinante para revelar melhoras de todos os componentes da capacidade funcional, favorecendo a realização das atividades da vida diária, entre elas, $O$ andar.

O PEG foi efetivo em promover mudanças no padrão do andar. Os componentes da capacidade funcional sofrem alterações com o avançar da idade (MATSUDO et al., 2003) e modificam o padrão de andar. Idosos geralmente apresentam diminuição da velocidade da marcha e redução de suas capacidades físicas, fato que sugere uma compensação a fim de aumentar a estabilidade e evitar quedas (HYLTON et al., 2003). Importante destacar que o maior número de quedas em idosos ocorre durante o andar (CARVALHO e COUTINHO, 2002; ZHEN-BO et al., 2007). O envolvimento em exercícios generalizados influenciou especialmente os parâmetros temporais do andar. Idosas revelaram aumento na cadência, na velocidade da passada e na porcentagem do tempo em suporte simples e redução na duração da passada e na porcentagem de tempo em duplo suporte. Por outro lado, o PEG não influenciou o comprimento da passada e do passo e a porcentagem do tempo de balanço. Estes resultados podem ser explicados pelas mudanças provocadas pelo PEG nos componentes da capacidade funcional, em especial a força muscular, o equilíbrio e a coordenação.

A força muscular permite aumento na força aplicada ao solo (SANTOS e PEREIRA, 2006) e, consequentemente, aumento da velocidade da passada e redução na duração da passada. Arantes et al. (2009) atribuíram a redução no tempo do duplo suporte ao aumento na força muscular. Farinatti e Lopes (2004) também argumentam o efeito do aumento da força muscular e da flexibilidade na cadência e no comprimento da passada e do passo. Apesar de que amplitude e cadência devam ser analisadas em conjunto, as mudanças na cadência observadas no presente estudo podem ser atribuídas à diminuição na duração da passada. Ainda, mudanças no equilíbrio dinâmico (SANTOS e PEREIRA, 2006) e na coordenação podem ter sido responsáveis pelo aumento da velocidade da passada. A diminuição na porcentagem do ciclo em duplo suporte, no contra-fluxo do processo de envelhecimento (FERRANDEZ et al., 1990), e o aumento em suporte simples indicam maior estabilidade na ação locomotora (PRINCE et al., 1997; WINTER, 1991; VIEL, 2001; ESTRÁZULAS et al., 2005) e revelam os efeitos do PEG no equilíbrio dinâmico. Assim, os 
achados deste estudo permitem inferir que as modificações encontradas no padrão do andar estão associadas aos ganhos em todos os componentes da capacidade funcional.

A velocidade da passada interfere na realização das atividades da vida diária e na incidência de quedas. Lopopolo et al. (2006) apontam que a redução de $0.1 \mathrm{~m} / \mathrm{s}$ na velocidade de andar de idosos promove decréscimo de $10 \%$ na habilidade deles em realizar atividades da vida diária. Em um estudo de coorte, Montero-Odasso et al. (2005) avaliaram o andar em diferentes velocidades e verificaram que o grupo de menor velocidade apresentou alta incidência de quedas, entre outros eventos. Ainda, o aumento na velocidade do andar pode estar refletindo o aumento na resistência aeróbia, observada no presente estudo e não diretamente trabalhada no PEG.

Os efeitos do PEG nas variáveis temporais do andar de idosas também podem ser explicados pelas características das atividades propostas. Inicialmente, realizar a maioria dos exercícios com acompanhamento musical, mesmo que não tenha sido solicitado, a sincronização entre o movimento e o ritmo acontece de forma subliminar. Além disso, quando dança e atividades rítmicas foram ministradas, o acompanhamento do ritmo foi solicitado. Cabe destacar que a Dança exige equilíbrio dinâmico e constante ajustamento às demandas ambientais, gera prazer e motivação nas participantes e deve ser recomendada para pessoas idosas (SONG et al., 2004). Estas características influenciam a mobilidade funcional por meio de mudanças no equilíbrio (EYIGOR et al., 2009) e, consequentemente, afetam o padrão de andar.

A análise de Regressão Múltipla para as variáveis da marcha nos momentos pré e pós-intervenção, mostra uma intrínseca relação entre as variáveis estudadas. Para a duração da passada e a cadência nos dois momentos, a análise revelou que, além do forte relacionamento, ambas foram associadas à coordenação no momento pós-intervenção. Este relacionamento explica a diminuição na duração da passada e o aumento na cadência promovido pelo PEG. Além da velocidade da passada aumentar após a intervenção, a forte associação entre os parâmetros do andar, em especial o comprimento da passada, e as variáveis demográficas, em especial a idade, foi modificada do momento pré para o momento pós-intervenção. Este resultado concorda parcialmente com Masshino e Carmano (2002), que relataram ser o 
comprimento da passada e a cadência os fatores determinantes do andar de idosos saudáveis.

Para a porcentagem de tempo no duplo suporte e no suporte simples, a análise de regressão múltipla revelou uma forte associação entre as variáveis antropométricas (estatura e dobra cutânea tricipital no momento pré e IMC no momento pós), os parâmetros do andar, o componente força no pré e o nível de atividade física de lazer no pós. Este intrincado relacionamento indica que a estabilidade do andar de idosos não pode ser atribuído apenas a fatores estruturais ou do próprio padrão de andar, mas que o exercício pode alterar este relacionamento.

O estudo 2 também apresenta algumas limitações. A não inclusão de participantes do gênero masculino devido, de modo geral, a uma pequena participação de homens em programas de exercícios físicos, que foi observada tanto no estudo 1 quanto no estudo 2. Outra limitação foi a falta de um grupo controle, diferentemente do que ocorreu no estudo 1. Apesar destas limitações o PEG mostrou-se efetivo para promover mudanças estruturais, funcionais e comportamentais e, portanto, pode ser recomendado como uma proposta de exercício para idosos.

\subsection{Conclusões}

Os resultados do presente estudo permitem concluir que: a) o programa de exercício generalizado de 4 meses não interferiu nas variáveis peso, estatura e IMC, mas foi positivo na redução da dobra cutânea tricipital em cerca de 7,5\%; b) houve expressivo aumento (aproximadamente 70\%) no nível de atividade física geral; c) todos os componentes da capacidade funcional melhoraram após a intervenção; d) o PEG foi efetivo em promover melhora nos parâmetros temporais do andar (duração e velocidade da passada, cadência, duração do suporte simples e duplo da passada); e) houve um forte relacionamento entre as variáveis preditoras temporais e espaciais do andar, as variáveis demográficas e estruturais. 


\section{CONSIDERAÇÕES FINAIS}

A presente tese buscou analisar o padrão de andar de idosas de acordo com o envolvimento em: a) diferentes tipos de exercício, considerando as características antropométricas, a capacidade funcional e o nível de atividade física; e b) um programa de exercícios generalizados. Para isso, dois estudos foram conduzidos. Esperava-se que os resultados do Estudo 1 permitissem recomendar a prática regular de um ou mais tipos de exercício para idosas. Esta expectativa pode ser satisfeita apenas em relação aos parâmetros espaciais do andar, pois as idosas que praticaram Dança apresentaram valores médios maiores para os comprimentos da passada e do passo. No Estudo 2, esperava-se que os efeitos do PEG fossem observados nas características antropométricas (diminuição da massa gorda e/ou aumento da massa magra), na capacidade funcional e nos parâmetros do andar. Esta expectativa foi satisfeita, pois as idosas reduziram os valores médios da dobra cutânea tricipital, melhoraram todos os componentes da capacidade funcional e os parâmetros temporais do andar.

Entretanto, alguns aspectos devem ser destacados. Mesmo considerando todos os aspectos de inclusão das participantes para o Estudo 1, inclusive praticar atividades (dança, musculação, hidroginástica e caminhada) a pelo menos 6 meses, a maior dificuldade encontrada neste estudo foi a falta do controle dos parâmetros do treinamento e da assiduidade, devido ao caráter de transversalidade do estudo. No Estudo 2, o controle desses parâmetros foi possível por se tratar de uma intervenção de 4 meses. Nesta perspectiva, o 
Estudo 2 se preocupou em traçar um programa de treinamento com exercício generalizado, buscando avaliar os parâmetros do andar de idosas, considerando também as características antropométricas, os componentes da capacidade funcional e o nível de atividade física, especialmente para favorecer o relacionamento com o Estudo 1.

Os resultados encontrados no Estudo 2 reforçam a necessidade de pesquisas de intervenção, visto que, de uma forma geral, a maioria das variáveis investigadas sofreram alterações positivas. Quanto à capacidade funcional do Estudo 2 todos os componentes obtiveram melhoras, enquanto que no Estudo 1, comparando todas as modalidades estudadas com o grupo controle, apenas o grupo da Musculação revelou maiores valores em força. A combinação dos resultados dos Estudos 1 e 2, em relação à capacidade funcional, indica que exercícios generalizados são recomendáveis para idosas, especialmente as sedentárias. As mudanças promovidas pelo PEG superaram os melhores resultados observados no Estudo 1, especialmente em relação a coordenação, flexibilidade, força e agilidade.

Para o padrão de andar, a intervenção melhorou sensivelmente as variáveis temporais; enquanto que, no Estudo 1, as variáveis espaciais apresentaram desempenho superior apenas no grupo Dança. Partindo dos achados em ambos os estudos, é pertinente afirmar que as características regionais do grupo Dança (forró e xaxado) poderiam ser incluídos em sessões de exercício generalizado, de forma a agregar melhoras nos parâmetros espaciais e temporais do andar de idosas. 


\section{REFERÊNCIAS}

ACSM/American College of Sports Medicine. Manual do ACSM para avaliação da aptidão física relacionada à Saúde. Editora Guanabara Koogan, 2006.

ALMEIDA, A. P. P. A.; VERAS, R. P.; DOIMO, L. A. Avaliação do equilíbrio estático e dinâmico de idosas praticantes de hidroginástica e ginástica. Revista brasileira de cineantropometria e desempenho humano, v. 12, n. 1, p. 5561, 2010.

AMADIO, A. C. Fundamentos biomecânicos para análise do movimento humano. São Paulo: Laboratório de Biomecânica: EEFUSP, 1996.

ANTONIAZZI, R. M. C; DIAS, J. F. S. O comportamento da força muscular de idosos setuagenários após programa de musculação. In: XXV Simpósio Internacional de Ciências do Esporte, 2002. São Paulo. Anais...São Paulo: CELAFISCS, 2002. p.10.

ARANTES, L.; COELHO, F.; SILVA, P.; COSTA, G.; GOBBI, L. T. B. Caracterização dos parâmetros temporo-espaciais da marcha em idosas praticantes de diferentes modalidades de exercícios. Revista Movimenta, v. 2, n.1, 2009.

BARBOSA, A. R.; SANTARÉM, J. M.; JACOB FILHO, W.; MARUCCI, M. F. N. Efeitos de um programa de treinamento contra resistência sobre a força muscular de mulheres idosas. Revista Brasileira de Atividade Física e Saúde, v. 5, n. 3, p.12-20, 2000.

BARBOSA, A. R.; SOUZA, J. M. P.; LEBRÃO, M. L.; LAURENTI, R.; MARUCCI, M. F. N. Anthropometry of elderly residents in the city of São Paulo, Brazil. Cadernos de Saúde Pública. V. 21, n. 6, p. 1929-1938, 2005.

BARROS, R. M. L.; BRENZIKOFER, R.; LEITE, N. J.; FIGUEROA, P. J. Desenvolvimento e avaliação de um sistema para análise cinemática tridimensional de movimentos humanos. Revista Brasileira de Engenharia Biomédica, v. 15, n. 1-2, p. 79-86, 1999.

BASSETTO, J. M.; ZEIGELBOIMI, B. S.; URKIEWICZ, A.; KLAGENBERG, K. F. Achados otoneurológicos em pacientes com doença de Parkinson. Revista Brasileira Otorrinolaringologia. v.74, n. 3, p. 350-355, 2008. 
BENEDETTI, T. R. B; MAZO, G. Z.; GOBBI, S.; AMORIM, M.; GOBBI, L. T. B.; FERREIRA, L.; HOEFELMANN, C. P. Valores normativos de aptidão funcional em mulheres de 70 a 79 anos Revista Brasileira de Cineantropometria \& Desempenho Humano, v. 9, n. 1, p. 28-36, 2007.

BOCALINI, D. S., SANTOS, R. N., MIRANDA, M. L. J. Efeitos da prática da dança de salão na aptidão funcional de mulheres idosas. Revista Brasileira de Ciência e Movimento, v.15, n.3, p.23-29. 2007.

BOYLE, P. A.; BUCHMAN, A. S.; WILSON, R. S.; BIENIAS, J. L.; BENNETT, D. A. Physical activity is associated with incident disability in community-based older persons. Journal of the American Geriatrics Society, v. 55, n. 2, p. 195-201, 2007.

BRACH, J. S.; SIMONSICK, E. M.; KRITCHEVSKY, S.; YAFFE, K.; NEWMAN, A. B. The association between physical function and lifestyle activity and exercise in the health, aging and body composition study. Journal of the American Geriatrics Society, v. 55, p. 502-509, 2004.

BRASIL. MINISTÉRIO DA SAÚDE. Vigitel Brasil 2006: vigilância de fatores de risco e proteção para doenças crônicas por inquérito telefônico. Brasília, 2007.

CARLI, S. C. $O$ idoso e a dança: aptidão física, auto-imagem e auto-estima. (Monografia de especialização). UFSC, Florianópolis, 2000.

CASPERSEN, C.J.; POWELL, K.E.; CHRISTENSON, G.M. Physical activity, exercise, and physical fitness: definitions and distinctions for health-related research. Public Health Reports - Archives, v. 100, n. 10, p. 126-131, 1985.

CARVALHO, A. M.; COUTINHO, E. S. F. Demência como fator de risco para fraturas graves em idosos. Revista de Saúde Pública, v. 36, n. 4, p. 448-454, 2002.

CARVALHO, J.; OLIVEIRA, J.; MAGALHÃES, J.; ASCENSÃO, A.; MOTA, J.; SOARES, J.M.C. Força Muscular em Idosos I - Será o Treino Generalizado Suficientemente Intenso para Promover o Aumento da Força Muscular em Idosos de Ambos os Sexos? Revista Portuguesa de Ciências do Desporto, v. 4, n. 1, p.51-7, 2004.

CARVALHO-ALVES, P. C.; MEDEIROS, S. Mecanismos moleculares envolvidos na sarcopenia e o papel da atividade física. In: CAMERON, L. C. e MACHADO, M. Tópicos Avançados em Bioquímica do Exercício. Rio de Janeiro: Shape, 2004.

CHODZKO-ZAJKO, W. J.; PROCTOR, D. N.; SINGH, M. A. F.; MINSON, C. T.; NIGG, C. R.; SALEM, G. J.; SKINNER, J. S. Exercise and physical activity for older adults. Medicine \& Science in Sports \& Exercise, v. 41, n. 7, p. 15101530, 2009.

CIPRIANI, N. C. S.; MEURER, S. T.; BENEDETTI, T. R. B.; LOPES, M. A. Aptidão funcional de idosas praticantes de atividades físicas. Revista Brasileira Cineantropometria e Desempenho Humano, v. 12, n. 2, p. 106111, 2010.

COELHO, F. G. M.; QUADROS JUNIOR, A. C; GOBBI, S. Efeitos do treinamento de dança no nível de aptidão funcional de mulheres de 50 a 80 anos. Revista da Educação Física/UEM Maringá, v. 19, n. 3, p. 445-451, 2008. 
CORDEIRO, R. C.; DIAS, R. C. Concordância entre observadores de um protocolo de avaliação fisioterapêutica em idosas institucionalizadas. Revista de Fisioterapia, v. 9, p. 69-77, 2002.

DAVID, A. C. Aspectos biomecânicos do andar em crianças: cinemática e cinética. Tese de Doutorado. Santa Maria: UFSM, 2000.

DOUGLAS, C. R. Tratado de fisiologia aplicada ä saúde. 5. Ed. São Paulo: Robe Editorial, 2002.

DIAS, V. K.; DUARTE, P. S. F. Idoso: níveis de coordenação motora sob prática de atividade física generalizada. Efdeportes, Buenos Aires, ano 10, n. 89, 2005. Disponível em: <http://www.efdeportes.com/>. Acesso em: 10 jun. 2009.

DUAYER, M. F. F.; OLIVEIRA, M. M. C.; GASPAR, J. C. Perfil dos pacientes com perdas funcionais e dependência atendidos pelo PSF no município de São Paulo. Revista da Escola de Enfermagem da USP, v. 41, n. 4, p. 42-49, 2007.

ESTRÁZULAS, J. A.; PIRES, R.; SANTOS, D. M.; STOLT, R. O. G.; MELO, S. I. L. Características biomecânicas da marcha em crianças, adultos e idosos. Efdeportes, Buenos Aires, ano. 10, n. 88, 2005. Disponível $<$ http://www.efdeportes.com/ >, acesso em 02 de fevereiro de 2010.

EYIGOR, S.; KARAPOLAT, H.; DURMAZ, B.; IBISOGLU, U.; CAKIR, S. A randomized controlled trial of Turkish folklore dance on the physical performance, balance, depression and quality of life in older women. Archives of Gerontology and Geriatrics, v. 48, p. 84-88, 2009.

FARINATTI, P. T. V.; LOPES, L. N. C. Amplitude e cadência do passo e componentes da aptidão muscular em idosos: um estudo correlacional multivariado. Revista Brasileira de Medicina do Esporte, v. 10, n. 5, p. 389394, 2004.

FERRANDEZ, A. M.; PAILHOUS, J.; DURUP, M. Slowness in elderly gait. Experimental Aging Research, v. 16, n. 2, p. 79-89, 1990.

FERREIRA, V. Atividade Física na Terceira Idade. O segredo da longevidade. Rio de Janeiro: Sprint, 2003.

FERREIRA, L.; GOBBI, S. Agilidade geral e agilidade de membros superiores em mulheres de terceira idade treinadas e não treinadas. Revista Brasileira de Cineantropometria e Desempenho Humano, v. 5, n. 1, p. 46-53, 2003.

FERREIRA, M.; MATSUDO, S.; MATSUDO, V.; BRAGGION, G. Efeitos de um programa de orientação de atividade física e nutricional sobre o nível de atividade física de mulheres fisicamente ativas de 50 a 72 anos de idade.

Revista Brasileira de Medicina do Esporte, v.11, n. 3, 2005.

FREITAS, E. V.; PY, L.; NERI, A. L. Tratado de Geriatria e Gerontologia. Rio de Janeiro: Guanabara Koogan, 2002.

FLORINDO, A. A.; LATORRE, M. R. D. O.; CONSTANTE, P.; TANAKA, T.; ZERBINI, C. A. F. Metodologia para a avaliação da atividade física habitual em homens com 50 anos ou mais. Revista de Saúde Pública, v.38, n. 2, p. 30714, 2004.

FRONTERA, W.R.; XAVIER, B. The benefits of strength training in the elderly. Science \& Sports, v. 17, p. 109-116, 2002. 
FRONTERA, W. R.; HUGHES, V. A.; KRIVICKAS, L. S.; KIM, S. K.; FOLDVARI M.; ROUBENOFF, R. Strength training in older women: early and late changes in whole muscle and single cells. Muscle Nerve, v. 28, n. 5, p. 601-608, 2003.

GILES-CORTI, B.; DONAVAN, R. J. Relative influences of individual, social environmental and physical environmental correlates of walking. American Journal of Public Health, v. 93 p.1583-9, 2003.

GOBBI, S. Atividade física para pessoas idosas e recomendações da organização mundial de saúde de 1996. Revista Brasileira de Atividade Física e Saúde, v. 2, n. 2, p. 41-49, 1997.

GOBBI, S.; ANSARAH, V. W. Functional fitness for aged people. In: the 1992, International Conference on Physical Activity, Fitness and Health: Conference abstracts, 1992, Toronto, Canadá. Conference Program and Poster Abstracts - The 1992 Conference on Physical Activity, Fitness \& Health, 1992.

GOBBI, S.; VILLAR, R.; ZAGO, A. S. Bases Teórico-Práticas do Condicionamento Físico. Rio de Janeiro: Guanabara Koogan, 2005.

GOBBI, S.; MENEZES, E.; TANAKA, K. Programas supervisionados de atividades físicas estão associados a maior nível de atividade física comparados com não supervisionados. Revista Brasileira de Atividade Física e Saúde, v. 12, p. 3-7, 2007.

GUCCIONE, A. A. Fisioterapia Geriátrica. 2. ed. Rio de Janeiro: Guanabara Koogan, 2002.

GUIMARÃES, L. H. C. T.; GALDINO, D. C. A.; MARTINS, F. L. M.; ABREU, S. R.; LIMA, M.; VITORINO, D. F. M. Avaliação da capacidade funcional de idosos em tratamento fisioterapêutico. Revista Neurociências, v.12, n. 3, p. 130-133, 2004.

HEYWARD, Vivian H. Avaliação física e prescrição de exercício. São Paulo: Manole, 2004.

HYLTON, B. M.; STEPHEN, R. L.; RICHARD, C. F. Age-related diferences in wlaking stability. Age and Aging, v. 32, n. 2, p.137-142, 2003.

HUNTER, G. R.; MCCARTHY, J. P.; BAMMAN, M. M. Effects of resistance training on older adults. Sports Medicine, v. 34, p. 329-48, 2004.

INSTITUTO BRASILEIRO DE GEOGRAFIA E ESTATÍSTICA, 2008 Disponível em: <http://www.ibge.gov.br/home/estatistica/populacao>, acesso 17 de novembro de 2009.

INSTITUTO DE CARDIOLOGIA DO RIO GRANDE DO SUL - Fundação Universitária de Cardiologia - Porto Alegre, RS. Perfis de Saúde - Brasil, 2006 - Modificações e suas Causas. Disponível em: <http://www.scielo.br/pdf/abc/v88n4/28.pdf/> acesso em 02 de fevereiro de 2008.

JACOB FILHO, W.; ISHIZUKA, M. A. Fatores de risco para quedas em idosos. In: Diogo, MJ, Neri, AL, Cachioni, M, organizadores. Saúde e Qualidade de Vida na Velhice, 2004.

JACOB FILHO, W.; ISHIZUKA, M. A. Avaliação e comparação dos fatores intrísecos dos riscos de quedas em idosos com diferentes estados funcionais. 
Revista de Fisioterapia da Universidade de São Paulo, v. 11, n. 1, p. 68-69, 2004.

KELL, R. T; BELL, G.; QUINNEY, A. Musculoskeletal fitness, health outcomes and quality of life. Sports Medicine, v. 31, p. 863-73, 2001.

LAMOUREUX, E. L.; SPARROW, W. A.; MURPHY, A.; NEWTON, R. U. The relationship between lower body strength and obstructed gait in communitydwelling older adults. American Geriatrics Society, v. 50, p. 468-473, 2002.

LANUEZ, S. V.; JACOB FILHO, W. Efeitos de dois programas de exercícios físicos nos determinantes de aptidão motora em idosos sedentários. Einstein, v. 6 n. 1 p.76-81, 2008.

LAUFER, Y. Effect of age on characteristics of forward and backward gait at preferred and accelerated walking speed. The Journals of Gerontology Series A: Biological Sciences and Medical Sciences, v. 60, p. 627-632, 2005.

LEBRÃO, M. L.; LAURENTI, R. Saúde, bem estar e envelhecimento: o estudo SABE no município de São Paulo. Revista Brasileira de Epidemiologia, v. 8, n. 2, p. 127-141, 2005.

LIBERMAN, L.; CUKIERT, A. Fisiologia e Fisiopatologia do Hormônio do Crescimento. São Paulo: Lemos Editorial, 2004.

LOHMAN, T. G.; ROCHE, A. F.; MARTORELL, R. Anthropometric standardization reference manual. Champaign: Human Kinetics Books; 1988.

LOPOPOLO, R. B.; GRECO, M.; SULLIVAN, D.; CRAIK, R. L.; MANGIONE, K. $\mathrm{K}$. Effect of therapeutic exercise on gait speed in community-dwelling elderly people: a meta-analysis. Physical Therapy, v. 86, n. 4, p. 520-540, 2006.

MARCHI NETTO, F. L. Aspectos biológicos e fisiológicos do envelhecimento humano e suas implicações na saúde do idoso. Revista Pensar a Prática, v.7, p.75-84, 2004. Disponível em: <http://www.revistas.ufg.br/index.php/fef/article>, acesso no dia 02 de maio de 2008.

MASSION, J. Movement, posture and equilibrium: interaction and coordination. Progress in Neurobiology, v. 38, p. 35-56, 1992.

MASSHIMO, A. M.; CARMANO, F. A. A marcha em idosos saudáveis. Arquivos de ciências da Saúde da Unipar, v. 6, n. 2, p. 117-121, 2002.

MASTROENI, M. F. Estado nutricional e consumo de macronutrientes de idosos da cidade de Joinville, SC. (Tese de Doutorado) Faculdade de Saúde Pública, Universidade de São Paulo, São Paulo, 2004.

MATSUDO, S. M; MATSUDO, V. K. R; BARROS NETO, T. L. Impacto do envelhecimento nas variáveis antropométricas, neuromotoras e metabólicas da aptidão física. Revista Brasileira Ciência e Movimento, v.10 n. 2, 15-26, 2000.

MATSUDO, S. M.; MATSUDO, V. K. R.; NETO, T. L. B. Atividade física e envelhecimento: aspectos epidemiológicos. Revista Brasileira de Medicina do Esporte, v. 7, n.1, p. 2-13, 2001.

MATSUDO, S. M. Envelhecimento, atividade física e saúde. Revista Mineira de Educação Física, v.10, n. 1, p. 193-207, 2002. 
MATSUDO, S. M.; MATSUDO, V. K. R.; BARROS NETO, T. L.; ARAÚJO, T. L. Evolução do perfil neuromotor e capacidade funcional de mulheres fisicamente ativas de acordo com a idade cronológica. Revista Brasileira de Medicina do Esporte, v. 9. n. 6. p. 365-376, 2003.

MAZO, G. Z.; LOPES, M. A.; BENEDETTI, T. R. B. Atividade Física e o Idoso. Editora Sulina: Porto Alegre, 2004.

MAZO, G. Z.; MOTA, J. A. P. S.; GONÇALVES, L. H. T. Atividade física e qualidade de vida de mulheres idosas. Revista Brasileira de Ciências do Envelhecimento Humano, v. 2, n. 1, p. 115-118, 2005.

MEANS, K. M.; RODELL, D. E.; O'SULLIVAN, P. S. Balance, mobility, and falls among community-dwelling elderly persons: Effects of a rehabilitation exercise program. American Journal of Physical Medicine and Rehabilitation, v. 84, n. 4, p. 238-250, 2005.

MENEZES, T. N ; MARUCCI, M. F. N. Antropometria de idosos residentes em instituições geriátricas, Fortaleza, CE. Revista de Saúde Pública, São Paulo, v. 39, n. 2, p. 169-175, 2005.

MENZ, H. B; LORD, S. R; FITZPATRICK, R. C. Age-related differences in walking stability. Age Ageing, v.32, p.137-42, 2003.

MILLS, P. M.; BARRETT, R. S.; MORRISON, S. Toe clearance variability during walking in young and elderly men. Gait \& Posture, v. 28, n. 1, p. 101-7, 2008.

MIYASIKE-DA-SILVA, V.; VILLAR, R.; ZAGO, A. S.; POLASTRI, P. F.; GOBBI, $S$. Nível de agilidade em indivíduos entre 42 e 73 anos: efeitos de um programa de atividades físicas generalizadas de intensidade moderada. Revista Brasileira de Ciências do Esporte, v.23, n.3, p.65-79, 2002.

MISIC, M. M.; VALENTINE, R. J.; ROSENGREN, K. S.; WOODS, J. A.; EVANS, E. M. Impact of training modality on strength and physical function in older adults. Gerontology, v .55, p.411-416, 2009.

MONTERO-ODASSO, M.; SCHAPIRA, M,; SORIANO, E. R.; VARELA, M.; KAPLAN, R.; CÂMERA, L. A.; MAYORGA, L. M. Gait velocity as a single predictor of adverse events in healthy seniors aged 75 year and older. The Journals of Gerontology Series A: Biological Sciences and Medical Sciences, v. 60, n. 10, p. 1304-1309, 2005.

MOREIRA, C. A. Atividade Física na Maturidade. Rio de Janeiro: Shape, 2001.

MOSTARDA, C.; WICHI, R.; SANCHES, I. C.; RODRIGUES, B., IRIGOYEN, M. C. Hipertensão e modulação autonômica no idoso: papel do exercício físico. Revista Brasileira Hipertensão, v.16, n. 1, p. 55-60, 2009.

NAHAS, M. V. Atividade Física e Saúde. Conceitos e sugestões para um estilo de vida ativo. 3. ed. Londrina: Midiograf, 2001.

NAKAMURA, Y., TANAKA, K., YABUSHITA, N., SAKAI, T., SHIGEMATSU, R. Effects of exercise frequency on functional fitness in older adult woman. Archives of Gerontology and Geriatrics, v. 42, n. 3, p. 355-357, 2006. 
NITZ, J. C.; HOURIGAN, S. R. Measuring mobility in frail older people: reliability and validity of the Physical Mobility Scale. Australasian Journal on Ageing, v. 25, n. 1, p. 31-35, 2006.

NUNES, R. R.; CLEMENTE, E. L. S.; PANDINI, J. A.; COBAS, R. A.; DIAS, V. M.; SPERANDEI, S.; GOMES, S.; GOMES, M. G. Confiabilidade da classificação do estado nutricional obtida através do IMC e três diferentes métodos de percentual de gordura corporal em pacientes com diabetes melito tipo 1. Arquivo Brasileiro de Endocrinologia e Metabologia, v. 55, n. 3, p. 360-367, 2009.

OCHALA, J.; LAMBERTZ, D.; HOECKE, J. V.; POUSSON, M. Effect of strength training on musculotendinous stiffness in elderly individuals. European Journal of Applied Physiology, v. 94, p. 126-133, 2005.

OSNESS, W. H. Functional fitness assessment for adults over 60 years. Reston: American Alliance for Health, Physical Education, Recreation and Dance, 1990.

PAPALÉO NETTO, M. Gerontologia: a velhice e o envelhecimento em visão globalizada. São Paulo: Atheneu, 2002.

PENDERGAST, D. R; FISHER, N. M; CALKINS, E. Cardiovascular, neuromuscular and metabolic alterations with age leading to frailty. Journal of Gerontology, v.48, p.61-7, 1993.

PERRY, J. Gait analysis: normal and pathological function. SLACK Incorporated, 1992.

PERSCH, L.N., UGRINOWITSCH, C., PEREIRA, G., RODACKI, A. L.F. Strength training improves fall-related gait kinematics in the elderly: $A$ randomized controlled trial. Clinical Biomechanics, v. 24, n. 10, p. 819-825, 2009.

POLASTRI, P. F.; SILVA, V. M.; VILLAR, R.; ZAGO, A.; GOBBI, S. Alterações nos níveis de coordenação de pessoas da terceira idade através de um programa de atividade física generalizada. Revista Motriz, Rio Claro - SP, v.5, n.1, p.115, 1999.

PRIOLI, A. C.; FREITAS JÚNIOR, P. B.; BARELA, J. A. Physical activity and postural control in elderly: Coupling between visual information and body sway. Gerontology, v. 51, p. 145-148, 2005.

PRIOLI, A. C.; CARDOZO, A. S.; FREITAS JÚNIOR, P. B.; BARELA, J. A. Task demand effects on postural control in older adults. Human Movement Science, v. 25, p. 435-446, 2006.

PRINCE, F.; CORRIVEAU, H.; HÉBERT, R.; WINTER, D. A. Gait in the elderly. Gait \& Posture, v. 5, n. 2, p. 128-135, 1997.

PY, L.; PACHECO, J. L.; SÁ, J. L. M. de; GOLDMAN, S. N. (Orgs.). Tempo de Envelhecer: Percursos e Dimensões Psicossociais. 1. ed. Rio de Janeiro: Nau Editora, 2004.

QUEIROZ, C. O.; MUNARO, H. L. R. Prevalência de sobrepeso e obesidade em idosas atendidas nos projetos da uesb. Revista Saúde.com, v. 4, n. 1, p. 43-49, 2008. 
RADOM-AIZIK, S.; HAYEK, S.; SHAHAR, I.; RECHAVI, G.; KAMINSKI, N.; BEN-DOV, I. Effects of aerobic training on gene expression in skeletal muscle of elderly men. Medicine in Science, Sports and Exercise, v. 37, n. 10, p. 1680-96, 2005.

RAMOS, L. M. Fatores determinantes do envelhecimento saudável em idosos em idosos residentes em centro urbano: projeto Epidoso. Cadernos de Saúde Pública, n. 19, p. 793-798, 2003.

REBElATtO, J. R.; CALVO, J. L.; OREJUELA, J. R.; PORTILLO, J. C. Influência de um programa de atividade física de longa duração sobre a força muscular manual e a flexibilidade corporal de mulheres idosas. Revista Brasileira de Fisioterapia, v. 10, n. 1, p. 127-132, 2006.

RIBEIRO, D. P.; MAZO, G. Z.; BRUST, C.; CARDOSO, A. S.; SILVA, A. H.; BENEDETTI, T. R. B.Programa de ginástica para idosos nos centros de saúde: avaliação da aptidão funcional. Revista Fisioterapia em Movimento, v.22, n. 3, p. 407-417, 2009.

ROSA, T. E. C.; Benício, M. H. A.; LATORRE, M. R. D. O.; RAMOS, L. R. Fatores determinantes da capacidade funcional entre idosos. Revista de Saúde Pública, v.37, n. 1, p. 40-8, 2003.

ROSE, J.; GAMBLE, J. G. Human Walking. 3. ed. Baltimore: Williams \& Wilkins, 2006.

SAAD, M.; BATISTELLA, L. R. (Eds.) Análise de Marcha: manual do CAMOSBMFR. São Paulo: Lemos Editorial, 1997.

SANCHEZ, M. A. A dependência e suas implicações para a perda de autonomia: estudo das representações para idosos de uma unidade ambulatorial geriátrica. Textos sobre Envelhecimento, v. 03, n. 03, p. 01-17, 2000.

SANTOS, M. A. M.; PEREIRA, J. S. Efeito das diferentes modalidades de atividades físicas na qualidade da marcha em idosos. Efdeportes, Buenos Aires, ano. 11, n. 102, 2006. Disponível em: <http://www.efdeportes.com/efd102/marcha.htm/>, acesso em 10 de maio de 2008.

SEBASTIÃO, E.; HAMANAKA, A. Y. Y.; GOBBI, S. Efeitos da prática regular de dança na capacidade funciona em idosas. In: CONGRESSO INTERNACIONAL DE EDUCAÇÃO FISICA E MOTRICIDADE HUMNA, 4.; SIMPÓSIO PAULISTA DE EDUCAÇÃO FíSICA, 10., 2005, Rio Claro. Resumos..., Motriz, Rio Claro, v. 11, n. 1, p. s165, 2005.

SEBASTIÃO É.; HAMANAKA, Á. Y. Y.;GOBBI, L. T. B.; GOBBI, S.; Efeitos da prática regular de dança na capacidade funcional de mulheres acima de 50 anos. Revista da Educação Física/UEM Maringá, v. 19, n. 2, p. 205-214, 2008.

SHEPHARD, R. J. Envelhecimento. Atividade física e saúde. Tradução: Maria Aparecida Pereira. São Paulo: Phorte, 2003.

SHIGEMATSU, R.; CHANG, M.; YABUSHITA, N.; SAKAI, T.; NAKAGAICHI, M.; $\mathrm{NHO}, \mathrm{H}$.; TANAKA, K. Danced-based aerobic exercise may improve indices of falling risk in older women. Age and Ageing, v. 31, p. 261-266, 2002. 
SHKURATOVA, N.; MORRIS, M. E.; HUXHAM, F. Effects of age on balance control during walking. Archives of Physical Medicine and Rehabilitation, v. 85, p. 582-8, 2004.

SHUMWAY-COOK, A.; WOOLLACOTT, M. H. Motor Control: theory and practical applications. Baltimore: Williams \& Wilkins, 1995.

SHUMWAY-COOK, A.; PATLA, A. E.; STEWART, A. L.; FERRUCCI, L.; CIOL, M. A.; GURALNIK; J. M. Assessing environmentally determined mobility disability: self-report versus observed community mobility. Journal of the American Geriatrics Society, v. 53, p. 700-704, 2005.

SIMONSICK, E. M.; FAN, E.; FLEG, J. L. Estimating cardiorespiratory fitness in well-functioning older adults: treadmill validation of the long distance corridor walk. Journal of the American Geriatrics Society, v. 54, p.127-132, 2006.

SILVEIRA, K. R. M.; MATAS, S. L. A.; PERRACINI, M. R. Avaliação do desempenho dos testes functional reach e lateral reach em amostra populacional brasileira. Revista Brasileira de Fisioterapia, v.10, n.4, p. 381386, 2006.

SILVA, A. H.; MAZO, G. Z. Dança para idosos: uma alternativa para o exercício físico. Cinergis, v. 8, n. 1, p. 25-32, 2007.

SILVA, N. L.; FARINATTI, P. T. V. Influência de variáveis do treinamento contra-resistência sobre a força muscular de idosos: uma revisão sistemática com ênfase nas relações dose-resposta. Revista Brasileira de Medicina do Esporte, v. 13, n. 1, p. 60-66, 2007.

SILVA, M. C.; ROMBALDI, J. A.; CAMPOS, A. L. P. Ordem dos exercícios físicos aeróbio e com pesos na aptidão física de mulheres acima de 50 anos. Revista Brasileira de Cineantropometria e Desempenho Humano, v. 12, n. 2, p. 134-139, 2010.

SOARES, A. V.; MATOS, F. M.; LAUS, L. H.; SUZUKI, S. Estudo comparativo sobre a propensão de quedas em idosos institucionalizados e nãoinstitucionalizados através do nível de mobilidade funcional. Fisioterapia Brasil, v. 4, n. 1, p. 13-17, 2003.

SONG, R.; JUNE, K. J.; KIM, C. G.; JEON, M. Y. Comparisons of motivation, health behaviors, and functional status among elders in residential homes in Korea. Public Health Nursing, v. 21, p. 361-371, 2004.

SPIRDUSO, W. W. Physical Dimensions of Aging. Champaign: Human Kinetics, 1995.

SPIRDUSO, W. W. Dimensões físicas do envelhecimento. São Paulo: Manole, 2005.

STESSMAN, J.; ROZENBERG, R. H.; MAARAVI, Y.; COHEN, A. Effect of exercise on ease in performing activities of daily living and instrumental activities of daily living from age 70 to 77 : the Jerusalem longitudinal study. American Geriatrics Society, vol. 50, n. 12, p. 1934-38, 2002.

STUNKARD, A. J.; FAITH, M. S.; ALISSOM, K. E. Depression and obesity. Society of Biological Phychiatry, v. 54, p. 330-337, 2003.

TEIXEIRA, D. C.; PRADO JUNIOR, S. R. R.; LIMA, D. F.; GOMES, S. C.; BRUNETTO, A. F. Efeitos de um programa de exercício físico para idosas 
sobre variáveis neuro-motoras, antropométrica e medo de cair. Revista Brasileira de Educação Física, v. 21, n. 2, p.107-120, 2007.

TRANCOSO, E. S. F.; FARINATTI, P. T. V. Efeitos de 12 semanas de treinamento com pesos sobre a força muscular de mulheres com mais de 60 anos de idade. Revista Paulista de Educação Física, v.16, n.2, p.220-9, 2002.

VALKEINEN, H.; ALEN, M.; HANNONEN, P.; HAKKINEN, A.; AIRAKSINEN, O.; HAKKINEN, K. Changes in knee extension and flexion force, EMG and functional capacity during strength training in older females with fibromyalgia and healthy controls. Rheumatology, v. 43, p. 225-228, 2004.

VAN EMMERIK, R. E. A.; MCDERMOTT, W. J.; HADDAD, J. M.; VAN WEGEN, E. E. H. Age-related changes in upper body adaptation to walking speed in human locomotion. Gait \& Posture, v. 22, p. 233-239, 2005.

VERAS, R. Envelhecimento populacional contemporâneo: demandas, desafios e inovações Revista de Saúde Pública, v. 43, n. 3 p. 548-554, 2009.

VERGHESE, J. Cognitive and mobility profile of older social dancers. Journal of the American Geriatrics Society, v. 54, n. 8, p. 1241-44, 2006.

VIEL, E. A Marcha Humana, a Corrida e o Salto: biomecânica, investigações, normas e disfunções. Tradução Maria Alice F. C. A. Barueri: Manole, 2001.

VIEIRA, A. S.; RABELO, R. J. Análise comparativa da velocidade de caminhada de mulheres idosas praticantes de ginástica, hidroginástica e dança sênior. Movimentum - Revista Digital de Educação Física, v. 2 - n.1, 2007.

VOORRIPS, L. E., RAVELLI, A. C., DONGELMANS, P. C., DEURENBERG, P., VAN STAVEREN, W. A. A physical activity questionnaire for the elderly. Medicine \& Science in Sports \& Exercise, v. 23, n. 8, p. 974-979, 1991.

WAGENAAR, R. C.; VAN EMMERICK, R. E. A. Resonant frequencies of the arms and legs identify different walking patterns. Journal of Biomechanics, $v$. 33, p. 853-861, 2000.

WILLIAMS, K.; BIRD, M. The aging mover: a preliminary report on constraints to action. International Journal of Aging and Human Development, v.34, n.3, p.241-55, 1992.

WINTER, D. A.; PATLA, A. E.; FRANK, J. S.; WALT, S. E. Biomechanical walking pattern changes in the fit and health elderly. Physical Therapy, v. 70, n. 6, p. 340-347, 1990.

WINTER, D. A. The Biomechanics and Motor Control of Human Gait: normal, elderly and pathological. Waterloo: University of Waterloo Press, 1991.

WINTER, D. A. Human balance and control during standing and walking. Gait \& Posture, v. 3, p. 193-214, 1995.

WHO - World Health Organization. Obesity and overweight. Geneva, 2004.

WHO - World Health Organization. Global Report on Falls Prevention in Older Age. Geneva, 2007.

ZAGO, A. S.; GOBBI, S. Valores normativos da aptidão funcional de mulheres de 60 a 70 anos. Revista Brasileira de Ciência e Movimento, v. 11, n. 2, p. 77-86, 2003. 
ZAITUNE, M. P. A.; BARROS, M. B. A.; CÉZAR, C. L. G.; CARANDONA, L.; GOLDBAUM, M. Fatores associados ao sedentarismo no lazer em idosos, Campinas, São Paulo, Brasil. Cadernos de Saúde Pública, v. 23, n. 6, p.1329-1338, 2007.

ZHEN-BO, C.; MAEDA, A., SHIMA, N.; KURATA, H.; NISHIZONO, H. The effect of a 12-week combined exercise intervention programo $n$ physical performance and gait 106 kinematics in community-dwelling elderly women. Journal of Physiological Anthropology, v. 26, n. 3, p. 325-332, 2007. 
ANEXO 1a: Termo de consentimento livre e esclarecido - Estudo 1

Pelo presente Termo de Consentimento Livre e Esclarecido,

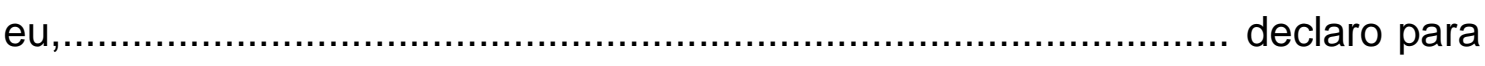

os devidos fins, que de livre e espontânea vontade, desejo participar da pesquisa: Efeitos do tipo de atividade física nos parâmetros do andar de idosos, sob a responsabilidade do pesquisador Jozilma de Medeiros Gonzaga. O meu consentimento para participar da pesquisa se deu após ter sido informado pelo pesquisador, de que:

1. A pesquisa se justifica, pois seu desenvolvimento gerará informações que possam melhorar a minha saúde, repercutindo também na saúde coletiva.

2. O objetivo da pesquisa é comparar os efeitos do tipo de atividade física nos parâmetros do andar de idosos.

3. Os dados serão coletados através de técnicas e instrumentos apropriados à pesquisa descritiva e exploratória.

4. À minha participação será estritamente voluntária, mesmo depois de minha autorização, tendo a liberdade de me retirar do estudo, antes, durante ou depois da finalização da coleta de dados, caso venha a desejar.

5. Será garantido o meu anonimato por ocasião da divulgação dos resultados e resguardado o sigilo de dados confidenciais.

6. Caso sinta necessidade de contatar o pesquisador durante e/ou após a coleta de dados, poderei fazê-lo pelo telefone (83) 33319785.

7. Ao final da pesquisa, se for do meu interesse, terei acesso ao conteúdo da mesma, podendo discutir os dados com o pesquisador.

Campina Grande de de 
ANEXO 1b: Termo de consentimento livre e esclarecido - Estudo 2

Pelo presente Termo de Consentimento Livre e Esclarecido, $\mathrm{eu}$ declaro para

os devidos fins, que de livre e espontânea vontade, desejo participar da pesquisa: Mudanças no padrão de andar, nas características antropométricas e na capacidade funcional de idosas após participação em programa de atividades físicas generalizadas, sob a responsabilidade do pesquisador Jozilma de Medeiros Gonzaga.

O meu consentimento para participar da pesquisa se deu após ter sido informado pelo pesquisador, de que:

1. A pesquisa se justifica, pois seu desenvolvimento gerará informações que possam melhorar a minha saúde, repercutindo também na saúde coletiva.

2. O objetivo da pesquisa é avaliar os parâmetros do andar de idosas sedentárias antes e após o desenvolvimento de um programa de atividade física generalizada, considerando também as características antropométricas, a capacidade funcional e o nível de atividade física.

3. Os dados serão coletados através de técnicas e instrumentos apropriados à pesquisa experimental.

4. À minha participação será estritamente voluntária, mesmo depois de minha autorização, tendo a liberdade de me retirar do estudo, antes, durante ou depois da finalização da coleta de dados, caso venha a desejar.

5. Será garantido o meu anonimato por ocasião da divulgação dos resultados e resguardado o sigilo de dados confidenciais.

6. Caso sinta necessidade de contatar $O$ pesquisador durante e/ou após a coleta de dados, poderei fazê-lo pelo telefone (83) 33319785.

7. Ao final da pesquisa, se for do meu interesse, terei acesso ao conteúdo da mesma, podendo discutir os dados com o pesquisador.

Campina Grande de de 
Nome: Código de Identificação

Data de nascimento: Idade: anos Endereço:

Cidade Estado:

Telefone:

Ocupação principal: Estado civil:

\section{ANAMNESE}

Preferência manual

Tabagismo: Cigarros/Dia: Álcool: Freqüência:

História ou caso de infarto do miocárdio

Angina pectoris e/ou insuficiência cardíaca

Diabetes mellitus do tipo 1, insulina-dependente

Numero de quedas nos últimos 12 meses

Problemas ósteo-mio-articulares que dificultem a locomoção

Problemas que interfere no equilíbrio

Uso regular de medicamentos (que interferem no equilíbrio):_Q Qual medicamento:

Outros medicamentos: 
ANEXO 3: Tradução do questionário modificado de Baecke para idosos (VOORRIPS et al., 1991).

Código do participante:

Data de coleta:

Escore:

\section{ATIVIDADE DA VIDA DIÁRIA}

1. Você realiza algum trabalho doméstico em sua casa?
0 . nunca (menos de uma vez por mês)
1. às vezes (somente quando um parceiro ou ajuda não está disponível)
2. quase sempre (às vezes com ajudante)
3. sempre (sozinho ou junto com
alguém)

2. Você realiza algum trabalho doméstico pesado (lavar pisos e janelas, carregar lixo, etc.)?
0 . nunca (menos que 1 vez por mês)
1. às vezes (somente quando um ajudante não está disponível)
2. quase sempre (às vezes com ajuda)
3. sempre (sozinho ou com ajuda)

3. Para quantas pessoas vocês faz tarefas domésticas em sua casa? (incluindo você mesmo, preencher 0 se você respondeu nunca nas questões 1 e 2)

4. Quantos cômodos você tem que limpar, incluindo, cozinha, quarto, garagem, banheiro, porão (preencher 0 se respondeu nunca nas questões $1 \mathrm{e}$ 2).

0 . nunca faz trabalhos domésticos

1. 1-6 cômodos

2. 7-9 cômodos

3. 10 ou mais cômodos

5. Se limpa algum cômodo, em quantos andares? (preencher se respondeu nunca na questão 4).

6. Você prepara refeições quentes para si mesmo, ou você ajuda a preparar?

0 . nunca

1. às vezes ( 1 ou 2 vezes por semana)

2. quase sempre ( 3 a 5 vezes por semana)

3. sempre (mais de 5 vezes por semana)
7. Quantos lances de escada você sobe por dia? (1 lance de escadas tem 10 degraus)

0 . eu nunca subo escadas

1. $1-5$

2. $6-10$

3. mais de 10

8. Se você vai para algum lugar em sua cidade, que tipo de transporte utiliza?
0 . eu nunca saio
1. carro
2. transporte público
3. bicicleta
4. caminhando

9. Com que freqüência você faz compras?

0 . nunca ou menos de uma vez por semana (algumas semanas no mês)

1. uma vez por semana

2. duas a 4 vezes por semana

3. todos os dias

10. Se você vai para as compras, que tipo de transporte você utiliza?

0 . Eu nunca saio

1. Carro

2. Transporte público

3. Bicicleta

4. Caminhando

ATIVIDADES ESPORTIVAS

Você pratica algum esporte?

Esporte 1:

Nome:

Intensidade:

Horas por semana:

Quantos meses por ano:

Esporte 2:

Nome:

Intensidade:

Horas por semana:

Quantos meses por ano:

ATIVIDADES DE LAZER

Você tem alguma atividade de lazer?

Atividade 1:

Nome:

Intensidade:

Horas por semana:

Quantos meses por ano: 


\section{INSTRUÇÕES}

Informações sobre esportes e outras atividades do tempo de lazer, são extraídas quanto o tipo de atividade, duração (horas por semana), freqüência (número de meses por ano), e a intensidade que a atividade foi normalmente realizada. A intensidade da atividade foi codificada baseada no trabalho de Bink et al. Estes códigos de intensidade são códigos sem unidade que foram originalmente baseados em gasto energético.

\section{CÁLCULOS}

A pontuação do questionário é dada como segue:

Escores das atividades diárias $=($ soma dos escores obtidos nas dez questões $\div 10$ ).

Escores do esporte $=0$ produto dos códigos para intensidade, horas por semana e meses por ano para cada atividade somada entre todas as atividades.

Escores para as atividades de tempo de lazer $=$ calculados similarmente aos escores do esporte.

Nota: desde que os escores do questionário não têm unidades inerentes (por exemplo, $\mathrm{kcal} / \mathrm{min}$, etc.), eles são designados a ser divididos dentro de quantias para propostas de classificação geral dentro da amostra dos quais os dados foram obtidos.

\section{EXEMPLO}

Escores do lar: A soma dos valores das respostas das 10 primeiras questões. Se as respostas de uma pessoa são como segue (número da questão: valor da resposta): 1:2, 2:2, 3:2, 4:3, 5:1, 6:3, 7:1, 8:1, 9:1, $10: 1$, a soma dos valores das respostas seria $2+2+2+3+1+3+1+1+1+1=17$. Os escores do lar seriam então $17 \div 10$, ou $1,7$.

Escores do esporte (ver tabela de códigos)

Boliche

Intensidade: o código é 0.890 (do n. 6: em pé, movimentos corporais e andar)

Horas por semana: 1-2 h/semana. Isto seria codificado como 1.5 .

Meses por ano: 6 meses/ano. Isto seria codificado como 0.42 .

Natação
Intensidade: o código é 1.890 .

Horas por semana:2-3 $\mathrm{h} / \mathrm{sem}$. Isto seria codificado como 2.5 .

Meses por ano: 10mês/ano. Isto seria codificado como 0.92 .

Escores do esporte: $(0.89 \times 1.5 \times 0.42)+(1.89 \times$ $2.5 \times 0.92)=0.561+4.347=4.91$

\section{Escore do lazer}

Nota: este escore é calculado da mesma forma do escore do esporte, usando os mesmos códigos para intensidade e duração.

Fazer tricô

Intensidade: o código é 0.297 (do número 2: sentado, movimentos de mãos ou braços.

Horas por semana: 10h/sem. Este seria codificado como 8.5.

Meses por ano: 12 mês/ano. Isto seria codificado como 0.92.

Escore do lazer $=0.297 \times 8.50 \times 0.92=2.32$

Escore do questionário $=$ escore do lar + escore do esporte + escore do lazer $=1.70+4.91+2.32$ $=8.93$

\section{Códigos para o questionário}

\section{Código de intensidade}

0 : deitado, sem carga - 0.028

1 : sentado, sem carga - 0.146

2: sentado, com movimentos de mãos e braços 0.297

3: Sentado, com movimentos corporais - 0.703

4: Em pé sem carga - 0.174

5: Em pé com movimentos de mãos e braços 0.307

6: Em pé, com movimentos corporais, caminhando -0.890

7: Caminhando, com movimentos corporais 1.368

8: Caminhando, movimentos corporais, pedalar, nadar -1.890

\section{Horas por semana}

1: Menos que $1 \mathrm{~h} / \mathrm{sem} \quad 0.5$

2: $1<2 \mathrm{~h} / \mathrm{sem} \quad 1.5$

$3: 2<3 \mathrm{~h} / \mathrm{sem} \quad 2.5$

4: $3-<4 / \mathrm{sem} \quad 3.5$

$5: 4-<5 \mathrm{~h} / \mathrm{sem} \quad 4.5$

$6: 5-<6 \mathrm{~h} / \mathrm{sem} \quad 5.5$

$7: 6-<7 \mathrm{~h} / \mathrm{sem} \quad 6.5$

8: $7-<8 \mathrm{~h} / \mathrm{sem} \quad 7.5$

9: 8 ou mais horas por semana 8.5

\section{Meses por ano}

1: Menos do que 1 mês/ano $\quad 0.04$

2: 1 -3 meses/ano 0.17

3: 4-6 meses/ano 0.42

4: 7-9 meses/ano 0.67

5: mais do que 9 meses por ano 0.92 
ANEXO 4: Percentis das variáveis antropométricas de IMC e DCT.

\begin{tabular}{|c|c|c|c|c|c|c|c|c|}
\hline \multirow{2}{*}{\multicolumn{2}{|c|}{ Idade }} & \multicolumn{7}{|c|}{ Percentil } \\
\hline & & 5 & 10 & 25 & 50 & 75 & 90 & 95 \\
\hline \multicolumn{9}{|l|}{ IMC $\left(\mathrm{Kg} / \mathrm{m}^{2}\right)$} \\
\hline & $60-69$ & 17,3 & 17,9 & 19,7 & 24,5 & 28,9 & 32,0 & 35,1 \\
\hline & $70-79$ & 14,9 & 16,7 & 19,9 & 24,1 & 27,6 & 30,3 & 31,6 \\
\hline & $80+$ & 14,5 & 15,8 & 18,1 & 21,2 & 24,5 & 29,1 & 32,1 \\
\hline \multicolumn{9}{|l|}{ DCT (mm) } \\
\hline & $60-69$ & 11,8 & 12,8 & 16,2 & 22,7 & 32,8 & 36,8 & 41,4 \\
\hline & $70-79$ & 9,7 & 11,9 & 15,6 & 20,7 & 28,2 & 32,2 & 33,8 \\
\hline & $80+$ & 7,3 & 10,2 & 11,8 & 18,3 & 25,1 & 31,2 & 35,5 \\
\hline
\end{tabular}

Obs.: Para o estudo desta tese, a classificação foi agrupada em cinco categorias: P $5=$ Desnutrição; $\mathrm{P}>5<25$ = Risco a desnutrição; $\mathrm{P}>25<75$ = peso adequado; $\mathrm{P}>75<95=$ Excesso de peso e $\mathrm{P}>95$ = Obesidade. 
ANEXO 5: Avaliação da capacidade funcional: níveis de aptidão funcional (Osness et al., 1990).

\section{Testes Motores da Bateria de testes da AAHPERD}

1) Teste de agilidade e equilíbrio dinâmico (agil): É um teste que envolve atividade total do corpo com movimentos para frente, mudanças de direção e posição do corpo (OSNESS et al., 1990). O participante inicia o teste sentado numa cadeira com os calcanhares apoiados no solo. Ao sinal de "pronto, já" move-se para a direita e circunda um cone que está posicionado a $1,50 \mathrm{~m}$ para trás e $1,80 \mathrm{~m}$ para o lado da cadeira (Figura 1), retornando para a cadeira e sentando-se. Imediatamente, o participante se levanta novamente, move-se para a esquerda e circunda o segundo cone, retornando para a cadeira e sentando-se novamente. Isto completa um circuito. $\mathrm{O}$ avaliado deve concluir dois circuitos completos.

Para certificar-se de que realmente o avaliado senta após retornar da volta ao redor do cone, ele deve fazer uma leve elevação dos pés retirandoos do solo. O tempo de execução é anotado. Serão realizadas duas tentativas (dois circuitos cada). O melhor tempo (o menor) será anotado em segundos como o resultado final.

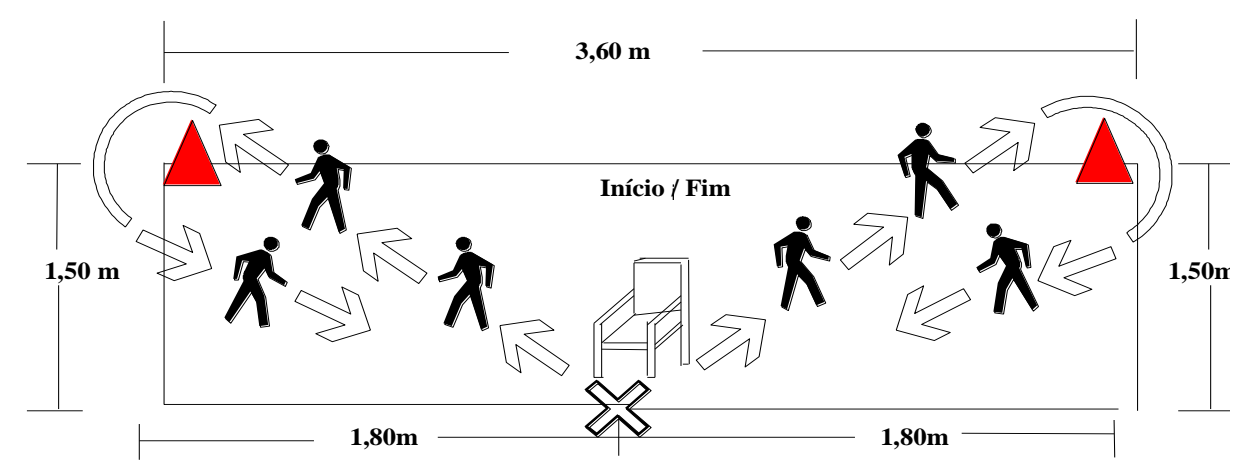

FIGURA 1 - Ilustração gráfica do teste de agilidade e equilíbrio dinâmico (adaptada de Osness et al., 1990).

2) Teste de coordenação (coo): $O$ teste de coordenação se concentra na eficiência neuromuscular dos braços e mãos (OSNESS et al., 1990). Para sua realização, um pedaço de fita adesiva, com $76,2 \mathrm{~cm}$ de comprimento, será fixada sobre uma mesa. Sobre a fita serão feitas 6 marcas com $12,7 \mathrm{~cm}$ eqüidistantes entre si, com a primeira e última marca a $6,35 \mathrm{~cm}$ de distância das extremidades da fita. Sobre cada uma das 6 marcas é afixado, perpendicularmente à fita, um outro pedaço de fita adesiva com $7,6 \mathrm{~cm}$ de comprimento (Figura 2). O participante senta-se de frente para a mesa e usa sua mão dominante para realizar o teste. Se a mão dominante fosse a direita, uma lata de refrigerante é colocada na posição 1 , a lata dois na posição 3 e, a lata três na posição 5. A mão direita é colocada na lata 1, com o polegar para cima, estando o cotovelo flexionado num ângulo de 100 a 120 graus. 


\section{Teste de Coordenação}

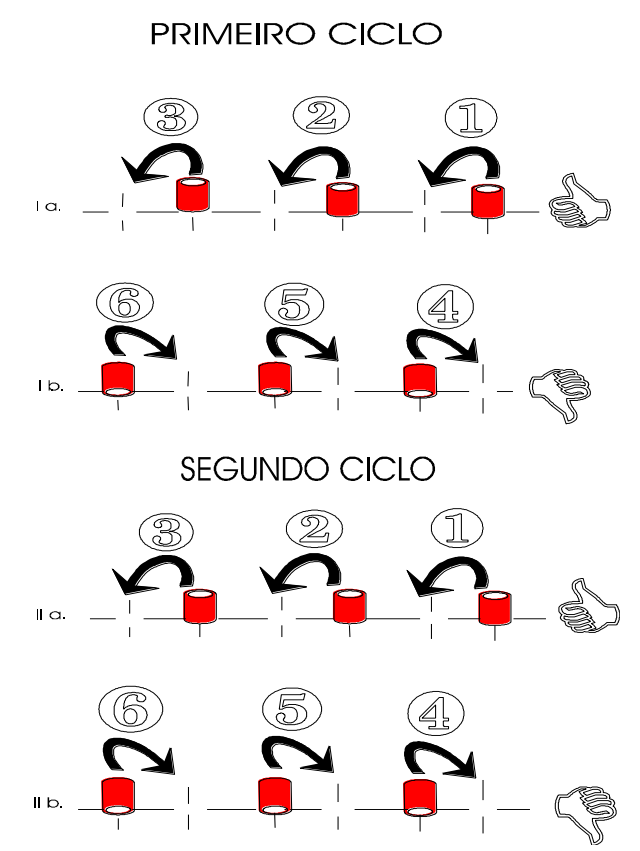

FIGURA 2: Ilustração gráfica do teste de coordenação (adaptada de Osness et al., 1990).

Quando o avaliador sinaliza, um cronômetro é acionado e, o participante, virando a lata inverte sua base de apoio, de forma que a lata 1 seja colocada na posição 2; a lata 2 na posição 4 e; a lata 3 na posição 6 . Sem perda de tempo, o avaliado, estando o polegar apontado para baixo, apanha a lata 1 e inverte novamente sua base, recolocando-a na posição 1 e, da mesma forma procede colocando a lata 2 na posição 3 e a lata 3 na posição 5 , completando assim um circuito. Uma tentativa equivale à realização do circuito duas vezes, sem interrupções. O cronômetro é parado quando a lata 3 é colocada na posição 5, ao final do segundo circuito. No caso do participante ser canhoto, o mesmo procedimento é adotado, exceto que as latas são colocadas a partir da esquerda - lata 1 na posição 6 , lata 2 na posição 4 e lata 3 na posição 2, e assim por diante. A cada participante são concedidas duas tentativas de prática, seguidas por outras duas válidas para avaliação, sendo estas últimas duas anotadas até décimos de segundo, e considerado como resultado final o menor dos tempos obtidos.

3) Teste de flexibilidade (flex): Uma fita adesiva de $50,8 \mathrm{~cm}$ é afixada no solo e uma fita métrica de metal também é afixada no solo perpendicularmente, com a marca de $63,5 \mathrm{~cm}$ (25 polegadas) diretamente colocada sobre a fita adesiva. Sobre a fita adesiva são feitas duas marcas eqüidistantes 15,2 cm (6 polegadas) do centro da fita métrica (Figura 3 ). $O$ participante, descalço, senta-se no solo, com as pernas estendidas, os pés afastados $30,4 \mathrm{~cm}$ (12 polegadas) entre si, os artelhos apontando para cima e os calcanhares centrados nas marcas feitas na fita adesiva. O zero da fita métrica aponta para o participante. Com as mãos, uma sobre a outra, o participante vagarosamente desliza a mão de baixo sobre a fita métrica tão distante quanto pode, permanecendo na posição final no mínimo por 2 segundos. $\mathrm{O}$ avaliador segura $\mathrm{o}$ joelho do participante para não permitir que 0 mesmo flexione. São oferecidas duas tentativas de prática, seguidas de duas 
tentativas de teste. O resultado final é dado pela melhor das duas tentativas anotadas (maior resultado).

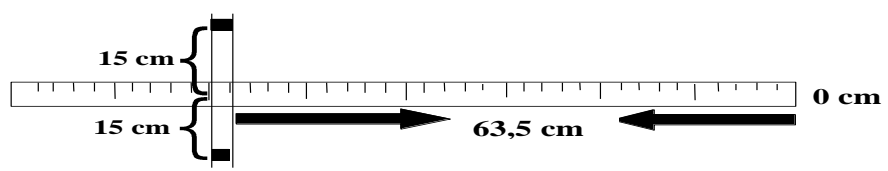

FIGURA 3: llustração gráfica do teste de flexibilidade (adaptada de Osness et al., 1990).

4) Teste de força e endurance de membros superiores (resisfor): Esse teste, também chamado de resistência de força envolve a força da parte superior do corpo, mas que também representa uma boa predição da força total (OSNESS et al., 1990). São utilizados halteres pesando $1,814 \mathrm{Kg}$ (peso para as mulheres) e $3,628 \mathrm{Kg}$ (peso para os homens). O participante senta-se em uma cadeira sem braços, apoiando as costas no encosto da cadeira, com o tronco ereto, olhando diretamente para frente e com a planta dos pés completamente apoiadas no solo. $\mathrm{O}$ braço dominante deve permanecer relaxado e estendido ao longo do corpo enquanto a mão não dominante apoiase sobre a coxa. O primeiro avaliador se posiciona ao lado do avaliado, colocando uma mão sobre o bíceps do mesmo e a outra suportando o halter, que é colocado na mão dominante do participante. O halter deve estar paralelo ao solo com uma de suas extremidades voltadas para frente. Quando o segundo avaliador, responsável pelo cronômetro, sinaliza com um "vai", o participante contrai o bíceps, realizando uma flexão do cotovelo até que o antebraço toque a mão do primeiro avaliador, que está posicionada no bíceps do avaliado. Quando esta tentativa de prática é completada, o halter é colocado no chão e 1 minuto de descanso é permitido ao avaliado. Após este tempo, o teste é iniciado, repetindo-se o mesmo procedimento, mas desta vez o avaliado realiza o maior número de repetições no tempo de 30 segundos, que é anotado como resultado final do teste.

5) Teste de resistência aeróbia geral e habilidade de andar (RAG): Este teste reflete a habilidade de andar em indivíduos idosos. Como uma avaliação da capacidade aeróbia, sua validade é moderada, mas comparável com outros testes de andar/correr (OSNESS et al., 1990). O participante é orientado para caminhar (sem correr) 804,67 metros, numa pista de atletismo de 400 m, o mais rápido possível. O tempo gasto para realizar tal tarefa é anotado em minutos e segundos, e transformados para segundos. 